\title{
DETERMINANTES DE LA MOVILIDAD OCUPACIONAL SEGMENTADA DE LOS INMIGRANTES NO COMUNITARIOS EN ESPAÑA
}

\author{
DETERMINANTS OF SEGMENTED OCCUPATIONAL MOBILITY OF \\ NON-EUROPEAN UNION IMMIGRANTS IN SPAIN
}

\author{
María Aysa-LAStra aysam@fiu.edu \\ Florida International University. EEUU \\ Lorenzo Cachón Rodríguez Icachon@cps.ucm.es \\ Universidad Complutense de Madrid. España
}

\begin{abstract}
RESUMEN
Los determinantes de la movilidad ocupacional de los inmigrantes se vienen estudiando de modo agregado para el conjunto del mercado de trabajo, tanto en la transición del país de origen al país de destino como en el proceso de asimilación económica posterior. Nuestro artículo analiza los determinantes de una pauta de movilidad segmentada y examina cuáles son significativos en los segmentos primario y secundario en ambas transiciones. Se utilizan datos de la Encuesta Nacional de Inmigrantes 2007 en España para elaborar modelos de regresión. Los resultados muestran que los determinantes más relevantes de la movilidad ocupacional de los inmigrantes en España que señalan los modelos generales desempeñan un papel diferente en los dos segmentos del mercado de trabajo, tanto en la notable movilidad ascendente y descendente que se produce dentro de ellos como en la escasa movilidad que se produce entre ellos.
\end{abstract}

\section{Palabras Clave}

España; Integración económica de los inmigrantes; Migración internacional; Movilidad ocupacional segmentada; Segmentación del mercado de trabajo.

\section{Abstract}

The determinants of immigrants' occupational mobility have been studied for the general labor market in both transitions, from home to the country of destination as the subsequent economic assimilation process. Our paper analyzes the determinants of a segmented occupational pattern and examines which determinants are significant in each of the primary and secondary segments at both transitions. It uses data from the National Immigrant Survey 2007 (Encuesta Nacional de Inmigrantes 2007) in Spain and includes multivariate regression models that explain the variations in occupational mobility. The results show that the most important determinants for the general model play a different role in the two segments of the labor market, both in the upward and downward mobility that occurs within the segments as in the limited mobility that occurs between them.

\section{KEYWORDS}

Economic Integration of Immigrants; International Migration; Labor Market Segmentation; Segmented Occupational Mobility; Spain. 


\section{INTRODUCCIÓN}

Los estudios que han analizado los determinantes de la movilidad ocupacional de los inmigrantes han seguido sobre todo la estela de los trabajos de Chiswick sobre la pauta de movilidad ocupacional en forma de "U" que siguen los inmigrantes en su proceso de asimilación en el mercado de trabajo del país de destino, con una fase descendente en su incorporación y una ascendente a lo largo de su progresiva "americanización". En otro lugar $^{1}$, a partir del caso de los inmigrantes no comunitarios en España, hemos señalado que deberíamos hablar de un pauta de movilidad ocupacional "segmentada" en forma de "U" porque la notable "fluidez" ocupacional, tanto en la transición descendente inicial entre el empleo en origen y el primer empleo en España, como en la contramovilidad posterior desde ese primer empleo al empleo "actual", se produce "dentro" de los segmentos primario y secundario del mercado de trabajo y es muy escasa la fluidez "fuera" de ellos en ambas transiciones. En este artículo examinaremos los determinantes de esa pauta segmentada de la movilidad ocupacional de los inmigrantes en España en las dos transiciones, intentando responder a la pregunta con la que terminábamos el artículo anterior: ¿Juegan un papel diferente en los distintos segmentos y en las dos transiciones los determinantes de las posiciones ocupacionales de los inmigrantes? Lo haremos a partir de la Encuesta Nacional de Inmigrantes 2007 que recoge datos retrospectivos de los inmigrantes en España.

Conviene recordar que durante la década 1997-2007 el empleo en España creció a un ritmo extraordinario: más del $5 \%$ en media anual (y la población ocupada inmigrante lo hizo a un ritmo anual medio del 147\%); España, que tenía tradicionalmente las cifras de paro más altas de la UE, se situaba a principios de 2007 en la media europea con una tasa de paro del $8 \%$, la más baja de los últimos treinta años. Pero el mercado de trabajo seguía siendo un mercado muy sensible al ciclo económico (España fue el país de la UE que más empleo creó en la fase expansiva del ciclo hasta 2007 y el que más desempleo genera durante la crisis actual que comienza a finales de 2007); muy precario (la proporción de precariedad, resultado de sumar parados y trabajadores temporales, era del $32 \%$ en 2007); con bajos salarios, especialmente en el caso de los temporales (que es un tercio menor que el de los trabajadores con contrato fijo); y con el $28 \%$ de la población ocupada en cuatro ramas de actividad de baja productividad (agricultura, construcción, hostelería y servicio doméstico) (Aysa-Lastra y Cachón 2011; 2012).

El artículo se estructura en cuatro epígrafes, aparte de la presente introducción. Se repasa, en primer lugar, la línea argumental de Chiswick y los principales desarrollos de la misma; a continuación sintetiza nuestro enfoque y los resultados de la pauta segmentada en forma de "U" y formula nuestra hipótesis de investigación sobre los determinantes de esa movilidad ocupacional segmentada; el epígrafe siguiente examina la

\footnotetext{
${ }^{1}$ Aysa-Lastra, M. y L. Cachón. "Movilidad ocupacional segmentada: el caso de los inmigrantes no comunitarios en España." Revista Española de Investigaciones Sociológicas (en prensa).
} 
fuente de datos y expone el método que se va a utilizar; a continuación se presentan los resultados de los modelos de regresión; y, por último, se sintetizan las conclusiones discutiendo los resultados en relación a la hipótesis planteada.

\section{Planteamiento teórico e hipótesis de investigación}

Tres artículos de B. R. Chiswick publicados a finales de los años setenta (1977; 1978 y 1979 ) enunciaron cómo "el progreso económico de los inmigrantes", tanto en sus salarios como en sus ocupaciones, es un "efecto de la americanización" y cómo se produce "una pauta aparentemente universal" en forma "U". Numerosos trabajos posteriores publicados con sus colaboradores han permitido contrastar este "único y relativamente sencillo modelo" en distintos países y períodos. Chiswick identifica dos determinantes claves de este progreso económico: transferibilidad y autoselección. Las mayores dificultades iniciales que tienen los inmigrantes para encontrar empleo son atribuidas a que el capital humano adquirido fuera es solo imperfectamente transferible al mercado de trabajo estadounidense (Chiswick 1997). La autoselección es una de las proposiciones estándar de la literatura económica para explicar el éxito económico de los inmigrantes: los migrantes económicos son descritos en promedio como más capaces, ambiciosos, agresivos y emprendedores que los individuos similares que optan por permanecer en su lugar de origen (Chiswick 1999). Esta "pauta aparentemente universal" tiene variaciones significativas según sea la motivación del inmigrante y otras circunstancias como el país de origen, la mayor o menor similitud entre los países de origen y de destino (Chiswick 1978) o el grupo racial o étnico (Chiswick 1979).

Numerosos trabajos han mostrado que la movilidad social (ocupacional) inicial de los inmigrantes en el país de destino es, sobre todo, una movilidad descendente a la que sigue un proceso de "contramovilidad" ascendente aunque sea limitada (McAllister 1995; Moddod 1998; Weiss et al. 2003; Redstone 2006 y 2008). El concepto de "contra-movilidad", referido al movimiento que lleva al inmigrante a recuperar su posición de partida, es básico en la sociología de la movilidad social desde la obra de Girod (1971), pero no se ha utilizado en los estudios sobre migraciones. Aquella movilidad descendente inicial se ha explicado por problemas de transferibilidad de cualificaciones (Chiswick 1997; Chiswick, Lee y Miller 2005); por la mayor o menor "proximidad" económica, cultural o lingüística entre el país de origen y el de destino que facilita o dificulta esa transferibilidad (Redstone 2006); o por deficiencias de capital humano inicial de los migrantes ya que se apunta que los nuevos flujos de inmigrantes son menos cualificados que los anteriores (Borjas 1995; 1999). Frente a la tesis de este último autor, Duleep y Regets (1997) muestran que lo que se produce es una mayor dificultad en la transferibilidad de las competencias de los inmigrantes. El nivel educativo de los inmigrantes es una variable fundamental pero su efecto sobre el logro salarial u ocupacional es muy distinto según haya sido adquirida en el país de origen o en el de destino. Friedberg (2000) ha 
mostrado que la educación y la experiencia laboral adquirida fuera son menos valoradas que el capital humano adquirido en el destino.

Algunos estudios han puesto el acento en características personales o familiares de los inmigrantes que pueden jugar un papel diferencial en el comportamiento de la "U" de Chiswick. Aunque gran parte de los trabajos se llevan a cabo eligiendo muestras exclusivamente de varones, el estudio del género tiene una presencia creciente (Tienda y Singer 1995; Raijman y Semyonov 1997; Powers y Seltzer 1998; Constant y Massey 2003; Adsera y Chiswick 2007; Suto 2009) e incluso Long (1980), retomando el título de un artículo de Chiswick, tituló el suyo "el efecto de la americanización de los salarios: algunas evidencias sobre las mujeres", y desarrolló el "Family Investment Model" para estudiar de modo sistemático las diferentes pautas de comportamiento de varones y mujeres inmigrantes. Otros autores han centrado sus investigaciones en el papel del estatus conyugal y en cómo tener hijos afecta negativamente a las mujeres (Cobb-Clark y Kossoudji 2000; Djamba et al. 2000). Por su importancia, merecen una mención aparte los trabajos que ponen de manifiesto cómo el origen nacional o étnico de los inmigrantes marca diferencias importantes en las pautas de asimilación en el mercado de trabajo en el país de destino (Allensworth 1997; Friedberg 2000; Chiswick et al. 2005; Redstone 2006; Adsera y Chiswick 2007; Barrett y Duffy 2008).

Hay otras investigaciones que han analizado la influencia sobre la pauta en forma de "U" de diversas características que tienen que ver con el proceso migratorio mismo, como el tipo y motivación de la inmigración (Chiswick et al. 2005; Redstone 2008; Reyneri y Fullin 2011), la situación de irregularidad administrativa de los inmigrantes en el país de destino (Powers y Seltzer 1998), la importancia del momento histórico en que se produce la inmigración (Redstone 2006), la situación del mercado de trabajo del país de destino en el momento de llegada de los inmigrantes (el cuándo) o las condiciones de los mercados de trabajo locales en que se insertan (el dónde) (Aslund y Rooth 2007), los procesos de autoselección en el retorno por parte de los más exitosos de los inmigrantes (Beenstock et al. 2010) y por parte de los que mantienen lazos sociales o económicos con el país de origen (Constant y Massey 2003). Se ha examinado también el papel de las redes sociales (Mullan 1989; Aguilera y Massey 2003; Massey y Aysa-Lastra 2011). En esta última dirección Hatton y Leigh (2011) muestran cómo, cuanto más consolidada está la tradición de la inmigración desde una región, mejores son los resultados económicos de los inmigrantes que llegan de esa región. Pero hay que recordar, en la estela de la argumentación de Portes (2000) sobre los posibles efectos negativos del capital social, que la densidad de estas redes sociales puede tener también efectos negativos (Nee y Sanders 2001; Reyneri y Fullin 2011). Los resultados de Mahuteau y Junankar (2008) apuntan a que las redes informales producen peores logros ocupacionales.

En España, la Encuesta Nacional de Inmigrantes de 2007, ha permitido contrastar algunas hipótesis de la literatura internacional. Diversos estudios han mostrado cómo los inmigrantes en España sufren una notable movilidad ocupacional descendente al incorporarse al mercado laboral, seguida de una parcial recuperación de la posición que tenían en la estructura ocupacional en su país de origen (Cachón 2009; Colectivo IOE 
2010). Pero se producen diferencias muy notables por países de origen y por género. Se ha señalado también la relevancia del nivel educativo para la movilidad ascendente de los inmigrantes en España (Caparrós y Navarro 2009) y de cómo el capital humano adquirido en España tiene una mayor rentabilidad marginal que el acumulado en origen (Sanromá et al. 2009). Stanek y Veira (2009) han analizado el descenso ocupacional como resultado de la emigración hacia España, poniendo el acento en el género, el capital humano y las redes sociales. Caparrós y Navarro (2010) subrayan los niveles educativos y zonas de origen de los inmigrantes. Simón at al. (2010) señalan un amplio conjunto de factores explicativos relevantes para estudiar la trayectoria ocupacional entre el país de origen, el primer empleo y el trabajo actual en España.

Nosotros hemos reexaminado (véase nota $n^{0}{ }^{0}$ ) la pauta de movilidad ocupacional en forma de "U" partiendo de un contexto teórico distinto: frente a la visión de "jerarquía social" que subyace en los trabajos de Chiswick y en gran parte de la literatura en este campo, nosotros partimos de una perspectiva de "estructura de clase" (el contraste es de Erikson y Goldthorpe (1993). Nuestra argumentación teórica se alimenta de dos fuentes: las teorías de la segmentación del mercado de trabajo y los desarrollos de la sociología de la movilidad que defienden la importancia de la movilidad relativa y la relevancia fundamental de la "fluidez" social. La primera podría sintetizarse siguiendo a Fassmann (1997:20) de la siguiente manera: "Se puede suponer que la idea neoclásica de un mercado de trabajo único es errónea y que el modelo de un mercado de trabajo segmentado es más apropiado. Las especiales condiciones jurídicas de reclutamiento y contratación de los trabajadores extranjeros y la desigual demanda y oferta de los trabajadores extranjeros son los elementos básicos de un mercado de trabajo segmentado étnicamente. Si los argumentos teóricos respectivos son verdaderos, es de esperar que los trabajadores extranjeros se ubiquen solo en algunas partes del mercado de trabajo y que esta asignación sea estable en el tiempo". Las aportaciones de la sociología de la movilidad social que nos sirven de apoyo pueden presentarse en dos grandes ideas, a partir de la síntesis de Goldthorpe (2010): las tasas absolutas de movilidad intergeneracional de clase, que muestran una variación considerable a lo largo del tiempo, son resultado de "efectos estructurales" exógenos: los factores clave son los que determinan las "formas" de las estructuras de clase y las tasas de variación desde las mismas. $\mathrm{Y}$, en segundo lugar, las tasas relativas parecen caracterizarse por un grado bastante sorprendente de invarianza: es decir, por una estabilidad temporal y por una semejanza transnacional sustantiva. Estos "regímenes endógenos de movilidad" o "fluidez" parecen determinar procesos que en gran medida son sistemáticos e independientes del contexto; es decir, procesos que operan de forma muy similar en una amplia variedad de sociedades.

Parafraseando la definición de "clase social" de Weber ([1922] 1969:142), hemos definido un segmento laboral como un "clúster de ocupaciones" que tienen algunas características comunes y entre las cuales es fácil y típico que se produzcan intercambios personales de posiciones ocupacionales. Algunos autores (Miller 1980; Rosenberg 1980; Boston 1990) han puesto de relieve la dificultad de delimitar los segmentos 
y de clasificar las ocupaciones (o grupos ocupacionales) dentro de ellos. Nosotros lo hemos resuelto anteriormente a través del resultado empírico de los datos: no dividimos los segmentos a priori (a partir de algún indicador 0 indicadores sobre salarios, prestigio, temporalidad, etc.) sino donde aparecen los límites de la circulación o de fluidez que nos proporcionan las razones de probabilidad que asocian unas celdas con otras en las tablas de movilidad de los dos momentos; es decir, de alguna manera los segmentos se "autodefinen" a través de la razones de probabilidad. Así han aparecido dos "clusters ocupacionales" que calificaremos como los segmentos primario y secundario. La aparición de estos segmentos confirma la existencia de diferentes "espacios de los posibles" en que los agentes desarrollan sus estrategias de movilidad, tal como se postula desde las teorías de la segmentación del mercado de trabajo (véase la nota n. $\left.{ }^{0} 1\right)$.

El examen de la movilidad relativa de los inmigrantes no comunitarios en España, analizada a través de razones de probabilidad, nos ha permitido señalar en las dos transiciones varias regularidades: 1) Los flujos ocupacionales son, sobre todo, la fluidez que se produce dentro de los segmentos primario y secundario y son muy escasos los que se producen "entre" ellos; 2) Tanto la movilidad descendente en la primera transición como la contramovilidad ascendente en la segunda se producen "dentro" de los segmentos, y ambas son escasas "fuera" de ellos. Estos rasgos permiten confirmar que existe una pauta de movilidad ocupacional segmentada en forma de "U" en la evolución de las posiciones ocupacionales de los inmigrantes no comunitarios en España, con una significativa "fluidez" dentro de los segmentos y un notable "cierre" entre ellos.

Pero se puede señalar también que esa pauta general de fluidez dentro y de cierre hacia fuera se reproduce en todas las variables consideradas, pero que muchas de ellas muestran una pauta de movilidad ocupacional segmentada en forma de "U" más o menos pronunciada o superficial. Los datos también nos han permitido confirmar la existencia de "variantes regulares" de este modelo general. Por ejemplo, la diferencia entre varones y mujeres. También distintas variables de capital humano han mostrado su relevancia para explicar distintos comportamientos de la "U", especialmente el mayor nivel educativo y su importancia para fijar a los inmigrantes de ese nivel educativo en el mercado primario. Algunas variables de la experiencia migratoria tienen gran importancia: el origen nacional de los inmigrantes marca diferencias significativas en la adscripción al mercado primario o secundario y en las pautas de asimilación en el mercado de trabajo en el país de destino; la motivación de la inmigración tiene también efectos significativos ya que, si es económica, los inmigrantes tienen mayores probabilidades de tener más descenso inicial y menos "contramovilidad" posterior y menor fluidez que los que no han llegado por motivos económicos. El hecho de estar o no en situación regular desde el punto de vista administrativo es otra variable que produce los mismos efectos negativos en la asimilación laboral y una relegación al mercado secundario. Las razones de probabilidad ponen de manifiesto la importancia ambivalente del capital social: las redes de familias y amigos ayudan al inmigrante 
recién llegado a encontrar un empleo con rapidez, pero este aspecto positivo viene acompañado de un aumento de las probabilidades de descenso ocupacional tanto en la primera como en la segunda transición y de una menor fluidez ocupacional en las dos transiciones. Para el análisis de los determinantes que se van a examinar en este artículo, conviene recordar presentar los datos de movilidad analizados en un texto previo (véase nota $n .^{0} 1$ ). En aquel, el análisis se hace desagregando los grupos ocupacionales a nivel de 1 dígito (9 categorías) pero aquí se presentan los resultados solo a nivel agregado para los dos segmentos que se identificaron (primario y secundario) (véase Tabla 1). Los datos sobre movilidad absoluta muestran la existencia de una movilidad ocupacional "estructural" (la señalada por los marginales en origen y destino) descendente de los inmigrantes en España en la primera transición y solo ligeramente ascendente en la segunda. Este hecho muestra que los inmigrantes se concentran sobre todo en ocupaciones del segmento secundario (facilitando una movilidad ocupacional absoluta ascendente de los autóctonos). La movilidad bruta de los inmigrantes entre posiciones ocupacionales refleja que en la primera transición tienen una movilidad claramente descendente y en la segunda una ligera contramovilidad ascendente. Incluso a este nivel de movilidad absoluta, es observable que los procesos de movilidad se producen sobre todo "dentro" de los segmentos y son muy escasos "entre" ellos. Pero es el examen de la movilidad relativa, medida a través de (logaritmos de) razones de probabilidad (odds ratios) quien nos permite desvelar un "régimen endógeno de movilidad" que apunta pautas sólidas de no-fluidez ocupacional fuera de los segmentos en las dos transiciones.

En este artículo pretendemos completar este análisis examinando los factores que pueden explicar esta pauta de movilidad ocupacional segmentada en forma de "U" que hemos observado y las "variantes regulares" del modelo que han aparecido. Por ello, a partir de los datos de la Encuesta Nacional de Inmigrantes 2007, intentamos contrastar la hipótesis siguiente:

Los determinantes más relevantes de la movilidad ocupacional descendente en la primera transición (entre la ocupación del último empleo en origen y la del primer empleo en España) y de la "contramovilidad" ascendente parcial en la segunda transición (entre el primer empleo en España y el empleo "actual" en 2007) que señalan los modelos generales, juegan un papel diferente en los segmentos primario y secundario del mercado de trabajo, tanto en la notable movilidad ascendente y descendente que se produce "dentro" de ellos como en la escasa movilidad que se produce "entre" ellos.

Si esta hipótesis se confirma, podremos mostrar los efectos "disimuladores" que tiene el análisis tradicional (que no desagrega por segmentos) porque acumula determinantes que tienen efectos distintos, e incluso en algunos casos opuestos, en los segmentos primario y secundario o que tienen una relevancia diferente en uno y otro segmento en las dos transiciones. 


\section{Tabla 1.}

Movilidad ocupacional (bruta y neta) entre segmentos (primario y secundario) de los inmigrantes no comunitarios en España en las dos transiciones.

Movilidad ocupacional bruta ( y número de casos).

\begin{tabular}{|c|c|c|c|c|c|}
\hline \multicolumn{6}{|c|}{ Primera transición } \\
\hline & \multicolumn{5}{|c|}{ Primera ocupación en España } \\
\hline & & Primario & Secundario & $\mathrm{N}$ & $\%$ \\
\hline \multirow{4}{*}{$\begin{array}{l}\text { País de } \\
\text { origen }\end{array}$} & Primario & 8,6 & 25,0 & 2.450 & 33,7 \\
\hline & Secundario & 2,5 & 63,8 & 4.830 & 66,3 \\
\hline & $\mathrm{N}$ & 810 & 6.470 & 7.280 & \\
\hline & $\%$ & 11,1 & 88,9 & & 100 \\
\hline \multicolumn{6}{|c|}{ Segunda Transición } \\
\hline & \multicolumn{5}{|c|}{ Última ocupación en España } \\
\hline & & Primario & Secundario & $\mathrm{N}$ & $\%$ \\
\hline \multirow{4}{*}{$\begin{array}{l}\text { Primera en } \\
\text { España }\end{array}$} & Primario & 6,2 & 2,2 & 339 & 8,4 \\
\hline & Secundario & 8,3 & 83,3 & 3.692 & 91,6 \\
\hline & $\mathrm{N}$ & 586 & 3.445 & 4.031 & \\
\hline & $\%$ & 14,5 & 85,5 & & 100 \\
\hline
\end{tabular}

Movilidad ocupacional neta (logaritmos naturales de razones de probabilidad)

\begin{tabular}{l|l|c|c}
\hline \multicolumn{4}{c}{ Primera transición } \\
\hline & \multicolumn{3}{|c}{ Primera ocupación en España } \\
\cline { 2 - 4 } & & Primario & Secundario \\
\hline \multirow{2}{*}{ País de origen } & Primario & 1,3 & 0,2 \\
& Secundario & $-0,7$ & 1,7 \\
\hline
\end{tabular}

Segunda Transición

\begin{tabular}{l|l|c|c}
\hline \multirow{2}{*}{} & \multicolumn{3}{|c}{ Última ocupación en España } \\
\cline { 2 - 4 } & & Primario & Secundario \\
\hline \multirow{2}{*}{ Primera en España } & Primario & 2,6 & 0,0 \\
& Secundario & 0,5 & 2,5 \\
\hline
\end{tabular}

Fuente: Elaboración propia, a partir de los microdatos de la ENI-2007 (véase texto citado en la nota n. ${ }^{0} 1$ ).

A) Cifras relativas calculadas sobre los datos ponderados.

B) Media no ponderada de los logaritmos naturales de las razones de probabilidad de las 16 casillas de cada segmento; ocupación de referencia: 5 . Trabajadores de servicios de restauración.

Estos datos sintetizan los cuadros $9 \times 9$ del artículo citado en la nota n. ${ }^{0} 1$. 


\section{Datos Y MÉTODOS}

La Encuesta Nacional de Inmigrantes (ENI-2007) recoge información sobre 15.465 personas nacidas fuera de España, mayores de 16 años, que vivían en España o tenían intención de hacerlo durante más de un año; es representativa de las personas que han nacido en Ecuador, Marruecos, Rumanía, y en las siguientes regiones: América Latina, África (con la excepción de Sudáfrica), Asia (con la excepción de Japón), América del Norte (Estados Unidos y Canadá) y Oceanía, la UE-15 más el Espacio Económico Europeo y Suiza. Fueron entrevistados entre noviembre de 2006 y febrero de 2007. La ENI-2007 contiene datos sobre características de los migrantes e historias migratorias e información retrospectiva sobre el último empleo de los migrantes en el país de origen, y el primer y el último empleo en España.

Para nuestro análisis hemos excluido a las personas nacidas fuera de la UE15, el EEE y Suiza, los nacionales españoles por nacimiento, las personas sin experiencia laboral en sus países de origen y a los que no tienen experiencia laboral en España. Por tanto, la muestra que utilizamos en nuestro análisis contiene datos sobre $7280 \mathrm{inmi-}$ grantes no nacidos en un país de la UE-15 que viven en España a principios de 2007. Para estudiar la movilidad ocupacional de inmigrantes no comunitarios entre su primer empleo y el actual en España, hemos seleccionado a los individuos que informaron que su trabajo actual era diferente a su primer trabajo en España $(n=4.031)$. Las características de los inmigrantes con un solo trabajo desde la llegada $(n=3.249)$ son similares a los que tienen varios trabajos.

\section{Medidas}

Nuestra variable dependiente es la movilidad ocupacional (de grupo ocupacional). El análisis se centra en la movilidad ocupacional entre y dentro de los segmentos del mercado de trabajo en las dos transiciones. Hemos diseñado las categorías para la variable dependiente, movilidad ocupacional ascendente, movilidad descendente e inmovilidad, mediante la comparación entre las ocupaciones del último empleo en el país de origen y del primer empleo en España, y desde la del primer empleo en España a la del empleo en el momento de la encuesta (para los inmigrantes no comunitarios con más de un empleo en España a partir de la llegada).

La ENI-2007 recopila información sobre una ocupación de cada empleo. Esta información se clasifica según la Clasificación Internacional Uniforme de Ocupaciones (CIUO-88) en su versión adaptada para España (CNO-94). Nosotros utilizamos la clasificación a nivel de un dígito para este análisis (no se incluyen Fuerzas Armadas):

1. Dirección de empresas y administraciones públicas

2. Técnicos y profesionales científicos e intelectuales

3. Técnicos y profesionales de apoyo 
4. Empleados de tipo administrativo

5. Trabajadores de servicios de restauración, personales, protección y vendedores de comercio

6. Trabajadores cualificados en la agricultura y en la pesca

7. Artesanos y trabajadores cualificados de las industrias manufactureras, la construcción y la minería

8. Operadores de instalaciones y maquinaria y montadores

9. Trabajadores no cualificados

Como nuestro argumento se centra en la segmentación del mercado de trabajo en algunos casos agrupamos estos grupos ocupacionales en dos segmentos, primario y secundario (a partir del análisis de las razones de probabilidad que muestran regularidades de asociación entre casillas en la tabla de movilidad: véase nota n. ${ }^{\circ}$ 1). En el mercado de trabajo primario ubicamos los grupos ocupacionales de las primeras cuatro categorías (uno a cuatro) y en el mercado de trabajo secundario los otros cinco (cinco a nueve). El quinto grupo ocupacional (Trabajadores de servicios de restauración, etc.) se puede identificar como una "zona de amortiguación" (Parkin 1978) que hemos agrupado en el segmento secundario por sus características.

Con el fin de comprender mejor la movilidad de los inmigrantes en un mercado de trabajo segmentado, en nuestro análisis incluimos mediciones del capital humano, experiencia migrante, capital social y características anteriores de empleo que han sido utilizados en investigaciones previas (Chiswick et al. 2005; Redstone 2006; Stanek y Viera 2009; Caparrós y Navarro 2010) y características sociodemográficas en el momento de su llegada a España (para el estudio de la primera transición) y en el momento de la encuesta (para la segunda transición).

Nuestro vector de variables de "Capital humano" está compuesto por: nivel educativo, y si el inmigrante tiene certificado de estudios. Para el nivel educativo podemos distinguir cuatro categorías: educación primaria o inferior, escuela media, secundaria y superior. Para el nivel más alto de educación alcanzado, conocemos si la persona tiene un certificado o diploma, y si este título ha sido homologado en España o adquirido en España ${ }^{2}$. Todas las variables se miden en el momento de la encuesta. Para el estudio de la primera transición, hemos ajustado las variables independientes y de control al momento de la llegada a España. La encuesta recolecta datos sobre el nivel educativo más elevado alcanzado, y si esos estudios fueron realizados en España. Hemos creado una proxy para el nivel educativo antes de llegar a España: a las personas que adquirieron su máximo nivel educativo en España, se les asignó el nivel de educación

\footnotetext{
${ }^{2}$ La encuesta contiene información sobre la lengua materna y el dominio del español (fluidez, fluidez parcial o no fluido). Sin embargo, no incluimos esta variable en el análisis multivariado para evitar la multicolinearidad. El 94\% de los inmigrantes de América Latina y el Caribe son hablantes nativos de español, mientras que más del $95 \%$ de los inmigrantes de otras nacionalidades no eran hablantes nativos de español.
} 
inmediatamente más bajo. En el caso del certificado o diploma, consideramos que los que completaron su nivel educativo más alto en sus países de origen tienen un diploma de sus países de origen, por lo que se creó una dummy para esta variable.

Nuestro vector de variables sobre "Experiencia migratoria" contiene la región de origen (en cinco grupos: resto de Europa (no UE-15 ni EEE), Marruecos, África sin Marruecos, América Latina, y Resto del mundo), año de llegada, ciudadanía o condición del inmigrante, razón para la migración (empleo u otro tipo), e intenciones de asentamiento (si los inmigrantes planean traer a su familia a España). Dado que la migración internacional es un fenómeno reciente de gran importancia, tanto por su magnitud como por el impacto que ha tenido en la sociedad y la economía española, para el estudio de la primera transición ocupacional dividimos en cuatro los períodos de su llegada: antes de 1998, período en el que España experimentó bajos niveles de inmigración; entre 1998 y 2000; entre 2000 y 2003, y entre 2004 y 2007; tres períodos de gran crecimiento económico y de la inmigración y el último marcado por los cambios en las políticas de inmigración e integración. Para la segunda transición utilizamos el tiempo (en años) que llevan en España en el momento de la entrevista. La encuesta tiene una pregunta sobre la documentación de los inmigrantes en el momento de la entrevista; hemos identificado tres grupos: ciudadanos de la Unión Europea-15 (que no han nacido en la UE-15, ya que a los nacidos en la UE-15 se les ha excluido) y titulares de tarjetas de residentes comunitarios; residentes permanentes y otros migrantes documentados (trabajadores temporales, estudiantes, refugiados y solicitantes de asilo); y los inmigrantes indocumentados (los que habían presentado sus solicitudes pero no había sido aprobada todavía, los que no habían presentado la solicitud, y aquellos que no tenían ninguna documentación de viaje o "no autorizada"). Para la primera transición (Tabla 3) hemos creado un proxy para la documentación a su llegada a España basándonos en esta información, en el año en que se les concedió la documentación, y en la duración de la estancia del inmigrante en España.

Dado que nuestro análisis se centra en la movilidad ocupacional, utilizamos como medida del capital social si los inmigrantes encontraron el primer empleo a través de sus redes sociales de familiares y amigos. También incluimos un vector de variables relacionadas con la "Experiencia de los inmigrantes en el mercado laboral". Para la movilidad ocupacional en la primera transición, utilizamos si el inmigrante llegó a España con una oferta de trabajo y, condicionada a esta variable, el tiempo que tardó en buscar el primer empleo (menos de 30 días, 30 a 90 , o más de 90 días); el estatus del empleo y el grupo ocupacional y el sector del último empleo en origen. Se agrupan los nueve grupos ocupacionales en cuatro grandes grupos, dos para el mercado de trabajo primario (categorías 1, 2 por una parte y 3 y 4 por otra) y dos para el mercado de trabajo secundario ( 6 y 7 por una parte y 8 y 9 por otra). También se agrupan en cuatro los sectores de actividad: agricultura y construcción, manufactura, servicios y se mantiene separado el servicio doméstico. Además, para los que han tenido más de un empleo en España, hemos añadido las siguientes variables: tiempo en el trabajo actual, número medio de contratos por año desde su llegada a España y número de veces que ha estado en situación de desempleo (nunca, una vez, más de una vez). 
Nuestro último vector de variables se relaciona con las "Características sociodemográficas" de los migrantes: sexo, edad (a la llegada a España y en el momento de la encuesta), estado civil (antes del viaje a España y en el momento de la encuesta), número de hijos antes de llegar a España y el número de menores de la edad de 16 años que viven en el mismo hogar en el momento de la encuesta.

\section{Métodos. Modelos de regresión}

En el Tabla 2 se observa que hay un rango de movilidad ocupacional de los migrantes en todas las características de los inmigrantes. Para observar la contribución de cada una de estas variables a la movilidad ascendente 0 descendente de los migrantes (vs inmovilidad) entre y dentro de los segmentos primario y secundario del mercado de trabajo, hemos estimado modelos logísticos multinomiales. En primer lugar, nos centramos en el análisis de la movilidad ocupacional del último empleo en origen al primer empleo en destino (Tabla 3) y luego, solo para aquellos con más de un empleo en España, nos fijamos en la movilidad entre el primer empleo y el empleo en el momento de la encuesta (Tabla 4). Para cada una de las dos transiciones ocupacionales estimamos cuatro modelos. En el primer modelo se estima la movilidad general descendente y ascendente (en todas las ocupaciones de origen y de destino en la tabla de la movilidad $9 \times 9$ ) sin tener en cuenta los segmentos del mercado de trabajo. Para el segundo modelo se agrupan las ocupaciones en los segmentos primario y secundario. Usamos esta tabla de movilidad 2x2 para estimar la probabilidad de movilidad desde el primario al secundario y del secundario al primario (vs permanecer en los segmentos). Para los modelos tercero y cuarto, se estiman razones de riesgo relativo para la movilidad ascendente y descendente dentro del segmento primario y dentro del segmento secundario (versus inmovilidad dentro de los segmentos).

Nuestra variable dependiente es mutuamente exclusiva y exhaustiva en todos los casos: los migrantes tienen movilidad ascendente, descendente 0 inmovilidad entre la ocupación anterior (última en origen o primera en España) y la posterior (primera en España para los que solo han tenido un empleo desde la llegada, y la del último empleo para los que han tenido varios empleos). Se estima una regresión logística multinomial de la siguiente manera ${ }^{3}$ :

$$
\ln \left(\frac{P_{\mathrm{i} M}}{P_{\mathrm{i} l}}\right)=\beta_{1} H C_{\mathrm{i}}+\beta_{2} M E_{\mathrm{i}}+\beta_{3} S C_{\mathrm{i}}+\beta_{4} L M_{\mathrm{i}}+\beta_{5} D_{\mathrm{i}}
$$

\footnotetext{
${ }^{3}$ Nuestro método es una regresión logística multinomial en vez de modelos de efectos fijos para eventos repetidos: en primer lugar, porque hemos querido analizar por separado las diferencias en las dos transiciones; en segundo lugar, porque queríamos preservar las muestras para ambas transiciones; y en tercer lugar, porque algunas variables son diferentes para cada una de las transiciones. Hemos ajustado nuestros modelos para el diseño de muestreo estratificado de la encuesta.
} 
Tabla 2.

Estadísticas descriptivas de las principales variables por ocupación de origen, la del primer empleo en España, la del empleo en el momento de la encuesta y proporción en el segmento secundario del mercado de trabajo.

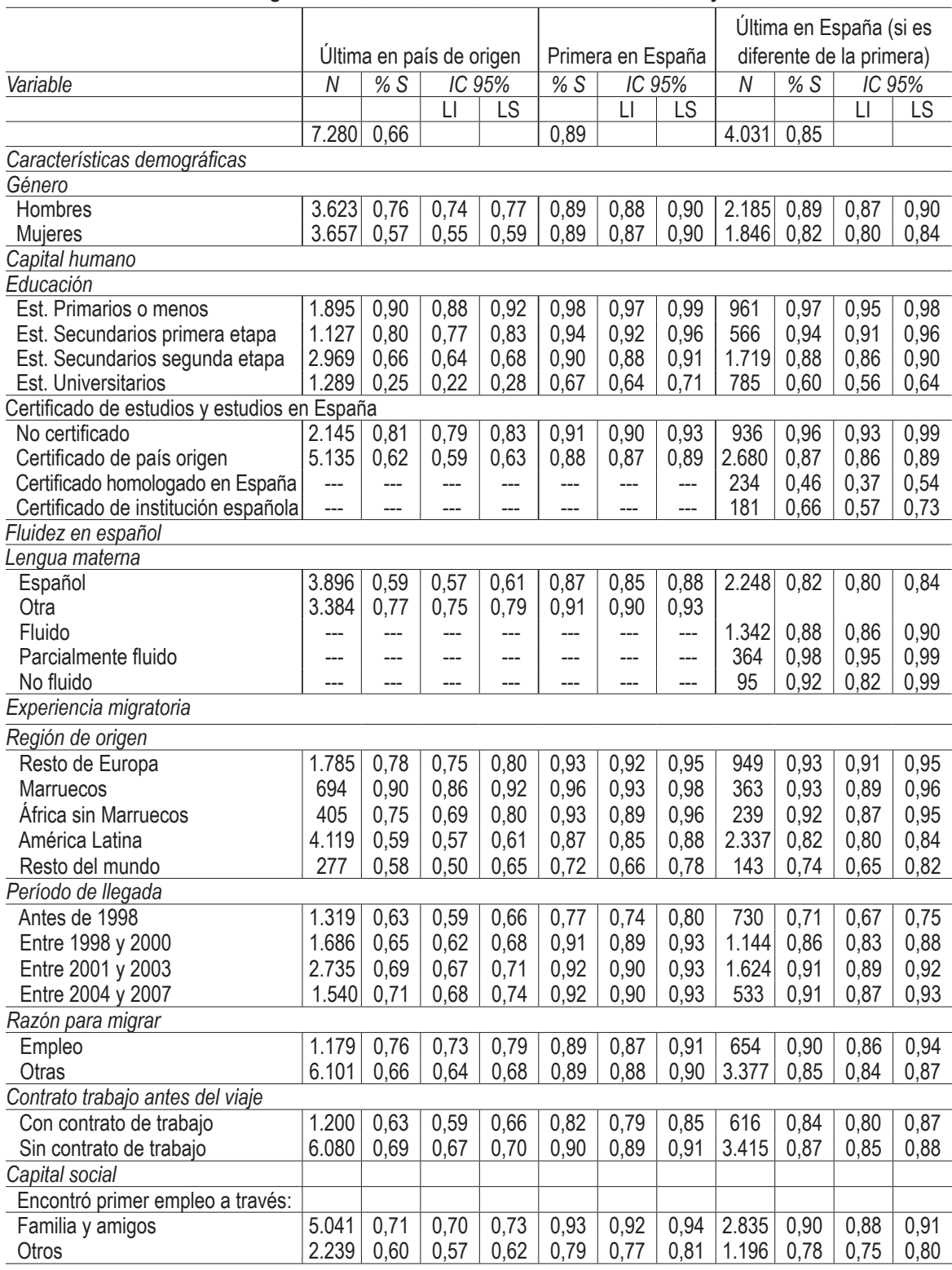

Fuente: Elaboración propia, a partir de microdatos de la Encuesta Nacional de Inmigrantes 2007.

Nota: S: segmento secundario; IC: Intervalo de confianza; LS: Límite superior: LI: Límite inferior. 
$P_{\mathrm{i} M}$ es la probabilidad de que un migrante $i$ experimente movilidad ocupacional descendente 0 ascendente $M$ entre la ocupación anterior y la posterior.

$P_{\mathrm{i} l}$ es la probabilidad de que un migrante $i$ experimente inmovilidad ocupacional entre la ocupación anterior y la posterior (categoría de referencia).

$H C_{\mathrm{i}}$ es un vector de variables de capital humano para el migrante $i$ (nivel educativo y credenciales).

$M E_{\mathrm{i}}$ es un vector de variables que indican las características relacionadas con la experiencia migratoria del migrante $i$ (país de origen, período de llegada, tiempo transcurrido desde la llegada y documentación de viaje).

$S C_{\mathrm{i}}$ indica si el inmigrante encontró su primer empleo en España a través de sus redes sociales de familiares y amigos, o no.

$L M_{\mathrm{i}}$ es un vector de variables que describen características del empleo anterior.

$D_{\mathrm{i}}$ es un vector de características demográficas (sexo, edad, estado civil y $\mathrm{n}^{0}$ de hijos).

\section{Resultados}

La presentación de los resultados del análisis multivariado se divide en dos partes. En primer lugar, se presentan los resultados de la movilidad ocupacional entre el último empleo en origen y el primer empleo en España (primera transición); y, en segundo lugar, los resultados de la movilidad ocupacional entre el primer y el último empleo en España en el momento de la encuesta (segunda transición). Para cada transición, vamos a discutir los vectores de variables independientes del modelo general de la movilidad ocupacional descendente y ascendente con relación a la inmovilidad. A continuación vamos a contrastar las diferencias en las probabilidades estimadas de los tres eventos (movilidad descendente, ascendente o inmovilidad) para cada uno de los modelos entre y dentro de los segmentos, y después estimaremos las diferencias con relación al modelo general. En otras palabras, vamos a contrastar sus resultados con los de los modelos para la movilidad ocupacional entre los segmentos y, sobre todo, con los de los modelos ascendente y descendente dentro de los segmentos primario y secundario. Para nuestro argumento no es tan importante discutir el valor de las razones de riesgo relativo de cada variable, sino las pautas que apuntan en los modelos ascendente y descendente (en relación con el de inmovilidad) en los distintos segmentos en las dos transiciones en comparación con su comportamiento en el modelo general.

\section{Determinantes de la movilidad ocupacional en la primera transición}

Capital humano

El nivel educativo está muy relacionado con el grupo ocupacional de los inmigrantes: tres cuartas partes de los graduados universitarios se encuentran en ocupaciones del 
segmento primario en origen (véase Tabla 2). Las columnas 2-3 de la Tabla 3 muestran las razones de riesgo relativo (RRR) para la movilidad ocupacional ascendente y descendente en relación con la inmovilidad en la primera transición. Los inmigrantes con estudios superiores tienen menos probabilidades de experimentar movilidad ocupacional descendente $(R R R=0,612)$ y más probabilidades de tener movilidad ascendente ( $R R R=1,524)$ que los inmigrantes con estudios secundarios, en relación con los que permanecen en el mismo grupo ocupacional. Por el contrario, los que tienen niveles educativos más bajos tienen menores probabilidades de movilidad ascendente y mayores de movilidad descendente. El nivel educativo es, además de un factor de movilidad (mayor o menor) de los individuos entre segmentos y entre ocupaciones, una característica propia de los segmentos (y por ello, definen las oportunidades iniciales de entrada en los mismos).

En la movilidad entre segmentos (columnas 4-5) las RRR muestran que los que tienen estudios inferiores a los secundarios tienen menos probabilidades de moverse de segmento, y que los que tienen estudios superiores están en la situación inversa porque tienen mayores probabilidades de cambiar de segmento ocupacional. Este patrón sugiere que aquellos con bajos niveles educativos tienden a permanecer en el mercado secundario. Los efectos de la educación para la movilidad ocupacional dentro del segmento primario (columnas 6-7) son muy reveladores: los que tienen estudios superiores tienen más probabilidades de bajar de grupo ocupacional y menos de subir que los que tienen estudios secundarios (es decir, lo contrario que en el modelo general). En el segmento secundario (columnas 8-9) los datos del nivel educativo no son muy significativos. Esto sugiere que la educación está fuertemente asociada con la colocación de los inmigrantes en ocupaciones del primario o del secundario, y que juega un papel de selección (y de exclusión) sobre todo en el segmento primario, pero una vez en estos segmentos (en origen) el nivel educativo no es importante para la movilidad dentro del segmento.

La comparación de los modelos generales y de los modelos entre y dentro de los segmentos muestra que el nivel educativo se comporta de modo algo distinto en los primeros que en los segundos, siendo especialmente relevante en el primario.

Los que tienen certificado de estudios de sus países de origen tienen una fuerte probabilidad de movilidad descendente inicial en España $(R R R=1,466)$ en comparación con los que no tienen certificado y una menor probabilidad ascendente, tanto en el modelo general como, sobre todo, entre segmentos.

\section{Experiencia migratoria}

De acuerdo con las RRR del modelo general, los inmigrantes africanos (Marruecos y resto de África) son más propensos a experimentar movilidad descendente y menos ascendente que los que provienen de la Europa no comunitaria; lo contrario ocurre con los inmigrantes latinos y del resto del mundo que tienen menos probabilidades de experimentar movilidad descendente inicial (para los latinos RRR=0,715). Entre segmentos los inmigrantes provenientes de África (sin Marruecos) y los latinos tienen más probabilidades de sufrir movilidad 
Tabla 3.

Razones de riesgo relativo de los modelos de regresión multinomial de movilidad ocupacional descendente y ascendente vs no movilidad por segmentos del mercado de trabajo entre el último empleo en origen y el primer empleo en España.

\begin{tabular}{|c|c|c|c|c|c|c|c|c|}
\hline \multirow[t]{2}{*}{ Variable } & \multicolumn{2}{|c|}{$\begin{array}{l}\text { Cambio en todas } \\
\text { las ocupaciones }\end{array}$} & \multicolumn{2}{|c|}{$\begin{array}{l}\text { Cambio entre } \\
\text { segmentos }\end{array}$} & \multicolumn{2}{|c|}{$\begin{array}{l}\text { Cambio dentro del } \\
\text { segmento primario }\end{array}$} & \multicolumn{2}{|c|}{$\begin{array}{l}\text { Cambio dentro } \\
\text { del segmento } \\
\text { secundario }\end{array}$} \\
\hline & Desc. & Asc. & Desc. & Asc. & Desc. & Asc. & Desc. & Asc. \\
\hline (1) & (2) & (3) & (4) & (5) & (6) & (7) & (8) & (9) \\
\hline \multicolumn{9}{|c|}{ Capital humano } \\
\hline \multicolumn{9}{|c|}{ Educación (Ref.=Est. Secundarios superiores) } \\
\hline \multirow[t]{2}{*}{ Est. Primarios o menos } & $1.323^{*}$ & $0.565^{\star * *}$ & $0.275^{\star \star \star}$ & $0.185^{\star \star \star}$ & 0,21 & $0.000^{\star \star \star}$ & 0,89 & 0,81 \\
\hline & $(0,17)$ & $(0,09)$ & $(0,04)$ & $(0,06)$ & $(0,20)$ & $(0,00)$ & $(0,11)$ & $(0,14)$ \\
\hline \multirow{2}{*}{ Est. Secundaros inferiores } & 1,23 & 0,83 & $0.549^{* * *}$ & 0,69 & $3.302^{*}$ & 1,32 & 1,09 & 0,91 \\
\hline & $(0,16)$ & $(0,13)$ & $(0,07)$ & $(0,19)$ & $(1,87)$ & $(1,11)$ & $(0,14)$ & $(0,16)$ \\
\hline \multirow[t]{2}{*}{ Est. universitarios } & $0.612^{* \star *}$ & $1.524^{*}$ & $2.146^{* * *}$ & $1.663^{*}$ & 1,46 & $0.339^{*}$ & 0,75 & 1,00 \\
\hline & $(0,08)$ & $(0,28)$ & $(0,23)$ & $(0,43)$ & $(0,50)$ & $(0,14)$ & $(0,15)$ & $(0,26)$ \\
\hline \multicolumn{9}{|c|}{ Certificado de estudios y estudios en España (Ref.=No Certificado) } \\
\hline \multirow{2}{*}{ Certificado de origen } & $1.466^{* \star *}$ & $0.745^{*}$ & 1,00 & $0.507^{* *}$ & 0,86 & $2.313+$ & 1,14 & $0.784+$ \\
\hline & $(0,15)$ & $(0,10)$ & $(0,10)$ & $(0,11)$ & $(0,31)$ & $(1,10)$ & $(0,12)$ & $(0,11)$ \\
\hline \multicolumn{9}{|c|}{ Experiencia migratoria } \\
\hline \multicolumn{9}{|c|}{ Región de origen (Ref.=Resto de Europa) } \\
\hline \multirow[t]{2}{*}{ Marruecos } & $1.572^{*}$ & 0,96 & 0,83 & 0,67 & $0.0887^{*}$ & $6.338+$ & 1,21 & 0,80 \\
\hline & $(0,31)$ & $(0,22)$ & $(0,17)$ & $(0,28)$ & $(0,11)$ & $(6,39)$ & $(0,22)$ & $(0,19)$ \\
\hline \multirow[t]{2}{*}{ África sin Marruecos } & $1.749^{*}$ & $0.478^{\star *}$ & $1.761^{\star *}$ & 0,59 & 0,25 & $0.0733^{*}$ & 1,17 & $0.411^{\text {** }}$ \\
\hline & $(0,45)$ & $(0,13)$ & $(0,36)$ & $(0,31)$ & $(0,24)$ & $(0,09)$ & $(0,26)$ & $(0,13)$ \\
\hline \multirow[t]{2}{*}{ América Latina } & $0.715^{\star *}$ & 1,05 & $1.526^{\star \star *}$ & 1,10 & 0,71 & $0.502+$ & $0.729^{* *}$ & 0,91 \\
\hline & $(0,08)$ & $(0,15)$ & $(0,14)$ & $(0,26)$ & $(0,24)$ & $(0,21)$ & $(0,08)$ & $(0,14)$ \\
\hline \multirow[t]{2}{*}{ Resto del mundo } & $0.396^{* \star *}$ & 1,32 & 0,96 & 1,65 & 0,38 & 0,98 & $0.496+$ & 0,86 \\
\hline & $(0,10)$ & $(0,37)$ & $(0,24)$ & $(0,59)$ & $(0,22)$ & $(0,56)$ & $(0,19)$ & $(0,31)$ \\
\hline \multicolumn{9}{|c|}{ Período de llegada (Ref.= antes 1998) } \\
\hline \multirow[t]{2}{*}{ Entre 1998 y 2000} & $1.558^{* *}$ & 0,82 & 1,01 & $0.549^{*}$ & 0,92 & $0.389+$ & $1.336+$ & 1,05 \\
\hline & $(0,23)$ & $(0,15)$ & $(0,13)$ & $(0,15)$ & $(0,36)$ & $(0,21)$ & $(0,22)$ & $(0,21)$ \\
\hline \multirow[t]{2}{*}{ Entre 2001 y 2003} & $1.540^{* *}$ & 0,78 & $0.770^{*}$ & $0.422^{* * *}$ & $1.871+$ & 0,64 & 1,27 & 1,01 \\
\hline & $(0,22)$ & $(0,13)$ & $(0,10)$ & $(0,11)$ & $(0,63)$ & $(0,28)$ & $(0,21)$ & $(0,20)$ \\
\hline \multirow[t]{2}{*}{ Entre 2004 y 2007} & $1.334+$ & $0.724+$ & $0.786+$ & 0,68 & 1,69 & 1,15 & 1,04 & 0,81 \\
\hline & $(0,20)$ & $(0,14)$ & $(0,12)$ & $(0,22)$ & $(0,69)$ & $(0,60)$ & $(0,18)$ & $(0,18)$ \\
\hline Ciudadanía y estatus inmigr & ante (Ref.= & ciudadan & $\mathrm{aEU})$ & & & & & \\
\hline Residentes permanentes & $1.460^{\star *}$ & 0,95 & 1,09 & 0,92 & 0,78 & $0.342+$ & $1.343+$ & 1,10 \\
\hline y otros docum & $(0,21)$ & $(0,17)$ & $(0,15)$ & $(0,26)$ & $(0,27)$ & $(0,20)$ & $(0,22)$ & $(0,23)$ \\
\hline Inmigrantes & $1.508^{\star * *}$ & $0.762+$ & $1.304^{*}$ & $0.480^{* *}$ & 1,21 & 1,30 & 1,19 & 0,83 \\
\hline indocumentados & $(0,17)$ & $(0,12)$ & $(0,14)$ & $(0,13)$ & $(0,43)$ & $(0,54)$ & $(0,15)$ & $(0,15)$ \\
\hline Razón de emigrar (Ref. $=0$ & ras distinta & as del emp & eo) loymen & & & & & \\
\hline Empleo & 0,98 & 0,80 & $0.625^{\star \star \star}$ & 0,74 & $2.471^{*}$ & $0.264+$ & 0,93 & 0,92 \\
\hline & $(0,12)$ & $(0,12)$ & $(0,08)$ & $(0,21)$ & $(1,00)$ & $(0,19)$ & $(0,11)$ & $(0,15)$ \\
\hline Intención de asentamient & n España & Ref. $=$ No & aer a la far & milia) & & & & \\
\hline Planes de traer a su & $1.392^{* *}$ & 1,07 & 1,03 & 0,88 & 0,89 & 1,05 & $1.194+$ & 1,15 \\
\hline familia & $(0,14)$ & $(0,13)$ & $(0,09)$ & $(0,20)$ & $(0,33)$ & $(0,52)$ & $(0,12)$ & $(0,15)$ \\
\hline Capital social & & & & & & & & \\
\hline Encontró primer empleo en & España $(R \in$ & ef.=otros) & & & & & & \\
\hline A través de la familia y & $1.817^{\star \star \star}$ & $0.772^{*}$ & 1,04 & $0.522^{\star * *}$ & 1,23 & 0,95 & $1.346^{* *}$ & 0,86 \\
\hline amigos & $(0,17)$ & $(0,09)$ & $(0,09)$ & $(0,10)$ & $(0,32)$ & $(0,31)$ & $(0,15)$ & $(0,12)$ \\
\hline
\end{tabular}


Tabla 3.

(Continuación)

\begin{tabular}{|c|c|c|c|c|c|c|c|c|}
\hline \multirow[t]{2}{*}{ Variable } & \multicolumn{2}{|c|}{$\begin{array}{l}\text { Cambio en todas } \\
\text { las ocupaciones }\end{array}$} & \multicolumn{2}{|c|}{$\begin{array}{l}\text { Cambio entre } \\
\text { segmentos }\end{array}$} & \multicolumn{2}{|c|}{$\begin{array}{l}\text { Cambio dentro del } \\
\text { segmento primario }\end{array}$} & \multicolumn{2}{|c|}{$\begin{array}{l}\text { Cambio dentro } \\
\text { del segmento } \\
\text { secundario }\end{array}$} \\
\hline & Desc. & Asc. & Desc. & Asc. & Desc. & Asc. & Desc. & Asc. \\
\hline (1) & (2) & (3) & (4) & (5) & (6) & (7) & $(8)$ & (9) \\
\hline \multicolumn{9}{|l|}{ Mercado de trabajo } \\
\hline \multicolumn{9}{|c|}{ Búsqueda de empleo (Ref.=dentro de 30 días) } \\
\hline \multirow{2}{*}{$\begin{array}{l}\text { Contratado en país de } \\
\text { origen }\end{array}$} & $0.462^{\star \star \star}$ & 0,80 & $0.719^{\star \star}$ & $0.460^{* \star}$ & $0.367^{* \star}$ & 1,22 & $0.653^{\star \star}$ & 0,84 \\
\hline & $(0,06)$ & $(0,12)$ & $(0,09)$ & $(0,13)$ & $(0,13)$ & $(0,53)$ & $(0,09)$ & $(0,15)$ \\
\hline \multirow{2}{*}{$\begin{array}{l}\text { Encontró empleo entre } \\
30 \text { y } 90 \text { días }\end{array}$} & 1,19 & 1,20 & 0,98 & 1,14 & $2.204+$ & 2,13 & 1,13 & 1,04 \\
\hline & $(0,15)$ & $(0,19)$ & $(0,11)$ & $(0,31)$ & $(0,90)$ & $(1,19)$ & $(0,14)$ & $(0,18)$ \\
\hline \multirow{2}{*}{$\begin{array}{l}\text { Encontró empleo en más } \\
\text { de } 90 \text { días }\end{array}$} & $0.797+$ & 0,99 & $0.705^{\star \star}$ & 0,88 & 1,07 & 1,69 & 0,86 & 0,95 \\
\hline & $(0,09)$ & $(0,14)$ & $(0,08)$ & $(0,21)$ & $(0,34)$ & $(0,67)$ & $(0,11)$ & $(0,15)$ \\
\hline \multicolumn{9}{|c|}{ Estatus de empleo (Ref.=empleadores y otros) } \\
\hline \multirow[t]{2}{*}{ Empleados } & $0.659^{* \star *}$ & $0.774^{*}$ & $0.797^{*}$ & 0,73 & 0,91 & $3.284^{\star *}$ & $0.707^{\star \star}$ & $0.620^{\star \star \star}$ \\
\hline & $(0,07)$ & $(0,10)$ & $(0,08)$ & $(0,17)$ & $(0,28)$ & $(1,41)$ & $(0,08)$ & $(0,08)$ \\
\hline \multicolumn{9}{|c|}{ Ocupación en empleo anterior (Ref.=Trabajadores Servicios restauracic } \\
\hline \multirow{2}{*}{$\begin{array}{l}\text { Directivos de empresas y } \\
\text { profesionales }\end{array}$} & $4.421^{* * *}$ & $0.0908^{\star \star * k}$ & $-\ldots$ & --- & --- & --- & --- & -.-- \\
\hline & $(0,65)$ & $(0,05)$ & --- & --- & $-\ldots$ & --- & --- & --- \\
\hline \multirow{2}{*}{$\begin{array}{l}\text { Técnicos de apoyo y } \\
\text { empleados administrativos }\end{array}$} & $6.522^{* * *}$ & $1.688^{*}$ & --- & --- & --- & --- & --- & --- \\
\hline & $(0,97)$ & $(0,40)$ & --- & --- & --- & --- & --- & --- \\
\hline \multirow{2}{*}{$\begin{array}{l}\text { Trabajadores cualificados } \\
\text { agricultura e industria }\end{array}$} & 0,86 & $3.718^{* * *}$ & -.- & --- & -.- & --- & --- & --- \\
\hline & $(0,12)$ & $(0,63)$ & --- & --- & --- & --- & --- & $-\ldots$ \\
\hline \multirow{2}{*}{$\begin{array}{l}\text { Trabajadores no } \\
\text { cualificados }\end{array}$} & $0^{\star \star *}$ & $3.782^{\star \star *}$ & $-\ldots$ & -.- & $-\ldots$ & $-\ldots$ & -.- & -.- \\
\hline & 0,00 & $(0,71)$ & -- & --- & --- & --- & --- & --- \\
\hline \multicolumn{9}{|c|}{ Sector de actividad del empleo anterior (Ref.=Servicios) } \\
\hline \multirow[t]{2}{*}{ Manufactura } & 1,06 & $1.333+$ & $0.415^{* \star \star}$ & 0,79 & 0,57 & 1,04 & 1,12 & $3.078^{\star \star *}$ \\
\hline & $(0,15)$ & $(0,21)$ & $(0,05)$ & $(0,21)$ & $(0,25)$ & $(0,56)$ & $(0,14)$ & $(0,48)$ \\
\hline \multirow{2}{*}{$\begin{array}{l}\text { Agricultura y } \\
\text { Construcción }\end{array}$} & $0.606^{* \star}$ & $0.485^{\star \star \star}$ & $0.292^{* \star *}$ & 0,92 & 0,64 & 0,15 & $0.306^{\star * *}$ & 0,87 \\
\hline & $(0,09)$ & $(0,08)$ & $(0,05)$ & $(0,29)$ & $(0,43)$ & $(0,17)$ & $(0,04)$ & $(0,15)$ \\
\hline \multirow{2}{*}{$\begin{array}{l}\text { Hogares con servicio } \\
\text { doméstico }\end{array}$} & 0,79 & $0.496^{* *}$ & $0.000^{* * *}$ & 0,73 & --- & --- & $0.171^{* * *}$ & 1,09 \\
\hline & $(0,31)$ & $(0,13)$ & 0,00 & $(0,46)$ & --- & -- & $(0,05)$ & $(0,26)$ \\
\hline \multicolumn{9}{|c|}{ Características demográficas } \\
\hline \multicolumn{9}{|l|}{ Género (Ref.=mujeres) } \\
\hline Hombres & $0.616^{* * *}$ & 0,82 & $0.417^{\star \star *}$ & 0,96 & $0.594^{*}$ & 0,90 & $0.815^{*}$ & 1,16 \\
\hline & $(0,06)$ & $(0,11)$ & $(0,04)$ & $(0,19)$ & $(0,16)$ & $(0,30)$ & $(0,08)$ & $(0,17)$ \\
\hline Edad a la llegada & 1,00 & 0,99 & 1,00 & 0,98 & 0,99 & $0.940^{\star *}$ & $1.009+$ & $0.987^{\star}$ \\
\hline & $(0,01)$ & $(0,01)$ & $(0,00)$ & $(0,01)$ & $(0,01)$ & $(0,02)$ & $(0,01)$ & $(0,01)$ \\
\hline Estatus marital antes del & je a Españ & (Ref. $=$ sol & tero) & & & & & \\
\hline Casado & 1,08 & 0,96 & $1.196+$ & $0.628+$ & 0,64 & 1,45 & 1,09 & 1,00 \\
\hline & $(0,11)$ & $(0,13)$ & $(0,11)$ & $(0,17)$ & $(0,21)$ & $(0,68)$ & $(0,12)$ & $(0,14)$ \\
\hline Número de hijos antes del & 1,01 & 0,99 & 1,02 & 0,91 & 1,08 & 1,03 & 0,99 & 1,05 \\
\hline viaje a España & $(0,05)$ & $(0,05)$ & $(0,04)$ & $(0,12)$ & $(0,17)$ & $(0,23)$ & $(0,04)$ & $(0,06)$ \\
\hline $\mathrm{N}$ & 6. & & 6.9 & & & & 4.4 & 11 \\
\hline F test & 4425 & $00^{\star \star \star}$ & 865.6 & $0^{* \star \star}$ & & & & \\
\hline
\end{tabular}

Fuente: Elaboración propia, a partir de microdatos de la Encuesta Nacional de Inmigrantes 2007.

${ }^{* * *} p<0.001,{ }^{* *} p<0.01,{ }^{*} p<0.05,+p<0.1$ 
descendente. Por segmentos las pautas de comportamiento responden en general a la misma lógica que los modelos generales con la excepción de los marroquíes en el primario: tienen menos probabilidades de descenso y más de ascenso que los europeos no comunitarios. Destaca también la menor probabilidad de los latinos de experimentar movilidad descendente en grupos ocupaciones del secundario y de los africanos no marroquíes de experimentar movilidad ascendente en el mismo segmento. Es decir, que las pautas que presenta la región de origen en el sistema de modelos generales de la primera transición se reproduce bastante bien en el segmento secundario, pero no así en el primario.

Las diferencias en la movilidad ocupacional por período de llegada podrían indicar que una entrada masiva de inmigrantes en el mercado laboral deteriora sus perspectivas ocupacionales. Esto puede ser debido a que ha descendido la "calidad" de las cohortes de inmigrantes (como señala, por ejemplo, Borjas 1995) y/o a que han ido descendiendo las oportunidades que ofrecía el mercado a los últimos llegados. Los que llegaron después de 1998 tienen más probabilidades de experimentar movilidad descendente y menos de tener movilidad ascendente. La pauta no se repite con claridad en los modelos de movilidad entre segmentos y dentro de los segmentos, que presentan comportamientos más variados. El flujo de inmigración hacia España se intensificó a partir de 1999 y progresivamente la presencia de inmigrantes en el mercado laboral comenzó a ser común. En 2005 tuvo lugar un importante proceso de regularización de inmigrantes indocumentados y comenzó a aplicarse una nueva regulación de los flujos migratorios; comenzó así un cambio de modelo en la gestión de los flujos y, probablemente, en el comportamiento de la movilidad ocupacional de los inmigrantes a su llegada a España; pero esto no se refleja en los datos (porque el trabajo de campo de la ENI-2007 está hecho a finales de 2006 y primeros de 2007). La crisis económica que comenzó en 2007 ha introducido otro factor de cambio muy importante (Cachón 2012).

En cuanto a la documentación para residir en España, los resultados muestran que aquellos que no tienen ciudadanía europea son más propensos a experimentar movilidad ocupacional descendente, tanto los residentes permanentes y otros residentes regularizados ( $R R R=1,460)$ como los indocumentados ( $R R R=1,508)$. En el modelo entre segmentos hay que destacar las menores probabilidades de movilidad ascendente que tienen los indocumentados. Los datos muestran una jerarquía de oportunidades desiguales en la que los indocumentados ocupan la posición con más probabilidades de movilidad ocupacional descendente y menores de ascendente. Para estos inmigrantes, la necesidad de conseguir un trabajo (cualquier trabajo) va más allá de conseguir medios de vida: es también la vía de intentar conseguir ser migrantes regularizados.

Los que emigraron a España por motivos de empleo son menos propensos, son especialmente menos propensos a sufrir movilidad descendente en el modelo entre segmentos, pero tienen una mayor propensión a sufrirla en el primario.

Se ha incluido una variable sobre las intenciones de asentamiento en España (plan para traer a sus familiares). Los resultados indican que los que planean asentarse son más propensos a experimentar movilidad descendente en el modelo general $(R R R=1,392)$, pero esta pauta es distinta en el modelo del segmento primario. 
Capital social

Los inmigrantes que encontraron su primer empleo a través de redes de familiares y amigos son más propensos a experimentar movilidad ocupacional descendente ( $R R R=1,817)$ y tienen menos probabilidades de experimentar movilidad ascendente $(R R R=0,772)$ que los que usaron otros canales de búsqueda de empleo. Este efecto se mantiene en los distintos modelos y es especialmente importante en la menor propensión a ascender entre segmentos y la mayor propensión a descender de grupo ocupacional en el secundario. Las redes familiares y de amigos ayudan al inmigrante recién llegado a encontrar un empleo con bastante rapidez, pero a costa de un descenso ocupacional respecto a su ocupación en origen.

\section{Mercado de trabajo}

La primera variable analiza la incorporación al mercado de trabajo en destino, distinguiendo si el inmigrante llegaba a España con un contrato firmado ya en origen y el tiempo que tardó en encontrar el primer empleo desde su llegada. Los que llegaron contratados en origen tienen menos probabilidades de experimentar movilidad descendente $(R R R=0,462)$ que los que encontraron empleo en los primeros 30 días en España. También son menos propensos a tener movilidad ascendente, sobre todo en el modelo entre segmentos. Esta pauta se repite en el secundario pero no en el primario. Los que encuentran empleo después de 90 días es menos probable que sufran movilidad descendente en el modelo general y entre segmentos. Los modelos apuntan a una mayor estabilidad ocupacional de los inmigrantes que llegan con contrato en origen y de los que más tiempo tardan en encontrar su primer empleo en España.

Los empleados son menos propensos a experimentar movilidad descendente 0 ascendente en todos los modelos, excepto en el ascendente en el segmento primario donde triplican a los empleadores en probabilidad de ascenso ocupacional.

Se ha incluido en el modelo la ocupación (como control) y el sector de actividad del último empleo en origen. Los que estaban empleados en la agricultura y la construcción y en el servicio doméstico en sus países de origen son menos propensos a tener la movilidad ocupacional (descendente y ascendente) que los que provenían del sector servicios y esta pauta se repite en los modelos de los segmentos. Los que provienen del sector manufacturero eran menos propensos a experimentar movilidad descendente entre segmentos y notablemente más ascendente en el secundario ( $R R R=3,078)$.

\section{Características demográficas}

Se observan diferencias sistemáticas en la movilidad ocupacional por género: los varones son menos móviles ocupacionalmente que las mujeres cuando llegan a España, especialmente a la baja $(R R R=0,616)$ en relación con aquellos que no cambian de ocupación. Esta pauta se repite prácticamente en todos los modelos. La edad a su llegada a 
España se relaciona negativamente con la movilidad ocupacional ascendente dentro de los segmentos primario y secundario. El estado civil muestra una relación significativa en el modelo entre los segmentos: los casados tienen más probabilidades de experimentar movilidad descendente y menos ascendente. El número de niños antes de la migración no tiene resultados significativos.

\section{Determinantes de la movilidad ocupacional en la segunda transición}

En esta sección presentamos el análisis de los determinantes de la movilidad ocupacional entre los inmigrantes en la segunda transición: entre su primer empleo en España y su empleo en el momento de la encuesta (noviembre 2006-febrero 2007) (Tabla 4).

\section{Capital humano}

El modelo general muestra que los que tienen estudios inferiores a secundarios tienen menos probabilidades de experimentar movilidad ocupacional ascendente en la segunda transición (para estudios elementales: $R R R=0,509$ ) que los que tienen estudios secundarios; por el contrario los que tienen estudios superiores son menos propensos a tener movilidad descendente (RRR=0,461) y más a tener movilidad ascendente. La importancia de la educación es muy distinta en otros modelos; son muy significativos en el modelo del secundario las menores probabilidades de ascenso que tienen los que tienen estudios inferiores a los secundarios y las nulas que tienen de promocionar en el primario los que tienen estudios elementales. Por el contrario, los que tienen estudios superiores tienen una propensión muy baja a descender dentro del segmento primario.

En la segunda transición se han incluido, además del hecho de tener (o no) certificado de estudios del país de origen, a los que han homologado esos certificados en España y a los que han obtenido un certificado en una institución educativa española. Las personas con certificado tienen más probabilidades de experimentar movilidad ocupacional ascendente en España que los que no lo tienen; se observa un gradiente en los efectos: la probabilidad de experimentar movilidad ocupacional ascendente es mayor para las personas con certificados homologados y más alto aún para las personas con certificados de una institución española. Aunque el gradiente no es igual, los certificados sí parecen muy importantes para facilitar la movilidad entre segmentos.

\section{Experiencia migratoria}

El efecto del país de origen para la movilidad descendente en el modelo general muestra menores probabilidades de descenso en comparación con la Europa no comunitaria en todos los orígenes, especialmente en resto del mundo y América Latina. Los africanos (sin Marruecos) tienen limitadas probabilidades de ascenso. Los razones estimadas en el modelo para la movilidad ocupacional entre los segmentos indican que los inmigran- 
Tabla 4.

Razones de riesgo relativo de los modelos de regresión multinomial de movilidad ocupacional descendente y ascendente vs no movilidad por segmentos del mercado de trabajo entre el primer empleo en España y el empleo actual.

\begin{tabular}{|c|c|c|c|c|c|c|c|c|}
\hline \multirow[t]{2}{*}{ Variable } & \multicolumn{2}{|c|}{$\begin{array}{c}\text { Cambio en todas las } \\
\text { ocupaciones }\end{array}$} & \multicolumn{2}{|c|}{$\begin{array}{l}\text { Cambio entre } \\
\text { segmentos }\end{array}$} & \multicolumn{2}{|c|}{$\begin{array}{l}\text { Cambio dentro del } \\
\text { segmento primario }\end{array}$} & \multicolumn{2}{|c|}{$\begin{array}{l}\text { Cambio dentro del } \\
\text { segmento secundario }\end{array}$} \\
\hline & Desc. & Asc. & Desc. & Asc. & Desc. & Asc. & Desc. & Asc. \\
\hline (1) & (2) & (3) & (4) & (5) & (6) & (7) & (8) & (9) \\
\hline \multicolumn{9}{|l|}{ Capital humano } \\
\hline \multicolumn{9}{|c|}{ Educación (Ref.=Est. Secundarios superiores) } \\
\hline \multirow[t]{2}{*}{ Est. Primarios o menos } & 0,97 & $0.509^{\star * \star}$ & $0.258^{*}$ & $0.483^{*}$ & 1,63 & $0.000^{\star \star \star}$ & 0,76 & $0.587^{\star \star}$ \\
\hline & $(0,21)$ & $(0,08)$ & $(0,15)$ & $(0,16)$ & $(2,75)$ & $(0,00)$ & $(0,14)$ & $(0,10)$ \\
\hline \multirow{2}{*}{$\begin{array}{l}\text { Est. Secundaros } \\
\text { inferiores }\end{array}$} & 0,95 & $0.641^{* *}$ & 0,62 & $0.563+$ & 0,33 & 2,84 & 0,71 & $0.708^{*}$ \\
\hline & $(0,21)$ & $(0,10)$ & $(0,28)$ & $(0,17)$ & $(0,52)$ & $(3,03)$ & $(0,15)$ & $(0,12)$ \\
\hline \multirow[t]{2}{*}{ Est. universitarios } & $0.461^{* * *}$ & 1,17 & 1,33 & $1.412+$ & $0.177^{\star *}$ & 0,89 & 0,72 & $0.718+$ \\
\hline & $(0,09)$ & $(0,18)$ & $(0,44)$ & $(0,27)$ & $(0,11)$ & $(0,45)$ & $(0,16)$ & $(0,13)$ \\
\hline \multicolumn{9}{|c|}{ Certificado de estudios y estudios en España (Ref.=No Certificado) } \\
\hline \multirow[t]{2}{*}{ Certificado de origen } & 1,26 & 1,23 & $0.415^{*}$ & $1.657+$ & 0,50 & 0,59 & 1,13 & 1,18 \\
\hline & $(0,23)$ & $(0,18)$ & $(0,15)$ & $(0,44)$ & $(0,69)$ & $(0,57)$ & $(0,20)$ & $(0,18)$ \\
\hline \multirow{2}{*}{$\begin{array}{l}\text { Certificado homologado } \\
\text { en España }\end{array}$} & 0,70 & $1.942^{*}$ & 0,80 & $4.026^{* * *}$ & 0,23 & 0,58 & 0,79 & $0.420^{*}$ \\
\hline & $(0,23)$ & $(0,53)$ & $(0,40)$ & $(1,31)$ & $(0,33)$ & $(0,57)$ & $(0,36)$ & $(0,15)$ \\
\hline \multirow{2}{*}{$\begin{array}{l}\text { Certificado de } \\
\text { institución española }\end{array}$} & 1,22 & $1.945^{*}$ & 1,01 & $2.656^{* *}$ & 0,23 & 0,42 & 1,48 & 1,27 \\
\hline & $(0,42)$ & $(0,55)$ & $(0,50)$ & $(0,95)$ & $(0,34)$ & $(0,40)$ & $(0,61)$ & $(0,42)$ \\
\hline \multicolumn{9}{|c|}{ Experiencia migratoria } \\
\hline \multicolumn{9}{|c|}{ Región de origen (Ref.=Resto de Europa) } \\
\hline \multirow[t]{2}{*}{ Marruecos } & 0,91 & 1,04 & 0,41 & $2.375^{*}$ & 0,02 & 1,56 & 0,76 & 1,17 \\
\hline & $(0,31)$ & $(0,25)$ & $(0,34)$ & $(0,89)$ & $(0,05)$ & $(2,22)$ & $(0,24)$ & $(0,29)$ \\
\hline \multirow[t]{2}{*}{ África sin Marruecos } & 0,60 & $0.571^{*}$ & 0,63 & 1,54 & $0.000^{* * *}$ & 0,82 & $0.374^{*}$ & 0,72 \\
\hline & $(0,26)$ & $(0,16)$ & $(0,43)$ & $(0,60)$ & $(0,00)$ & $(0,93)$ & $(0,16)$ & $(0,21)$ \\
\hline \multirow[t]{2}{*}{ América Latina } & $0.649^{*}$ & 1,15 & 0,96 & $1.500^{*}$ & 0,62 & 0,88 & 0,89 & 0,93 \\
\hline & $(0,12)$ & $(0,16)$ & $(0,30)$ & $(0,31)$ & $(0,59)$ & $(0,65)$ & $(0,15)$ & $(0,14)$ \\
\hline \multirow[t]{2}{*}{ Resto del mundo } & $0.243^{*}$ & 1,38 & 0,50 & 1,52 & 0,21 & 0,25 & 0,35 & 1,38 \\
\hline & $(0,14)$ & $(0,47)$ & $(0,55)$ & $(0,75)$ & $(0,29)$ & $(0,26)$ & $(0,23)$ & $(0,53)$ \\
\hline \multirow{2}{*}{$\begin{array}{l}\text { Tiempo en España } \\
\text { (en años) }\end{array}$} & $0.964+$ & $1.030+$ & 0,95 & 1,03 & 0,96 & 1,00 & 0,98 & 1,00 \\
\hline & $(0,02)$ & $(0,02)$ & $(0,04)$ & $(0,02)$ & $(0,07)$ & $(0,05)$ & $(0,02)$ & $(0,02)$ \\
\hline \multicolumn{9}{|c|}{ Ciudadania y estatus migratorio (Ref.= ciudadania UE) } \\
\hline Residentes permanentes & 1,28 & $0.677^{\star *}$ & 0,86 & 0,81 & 0,67 & $0.251^{\star *}$ & 1,15 & $0.785+$ \\
\hline y otros documentados & $(0,22)$ & & $(0,23)$ & $(0,14)$ & $(0,43)$ & $(0,13)$ & $(0,20)$ & $(0,12)$ \\
\hline Inmigrantes & 1,09 & $0.462^{* \star *}$ & 0,42 & $0.327^{* *}$ & & & 0,79 & $0.611^{*}$ \\
\hline indocumentados & $(0,34)$ & $(0,10)$ & $(0,22)$ & $(0,14)$ & & & $(0,22)$ & $(0,14)$ \\
\hline Razón de emigrar (Ref & ras distin & emplec & yyment) & & & & & \\
\hline Empleo & 1,23 & 1,05 & 0,70 & 0,72 & $0.0474^{*}$ & 0,59 & 1,36 & 1,13 \\
\hline & $(0,25)$ & $(0,16)$ & $(0,35)$ & $(0,21)$ & $(0,07)$ & $(0,35)$ & $(0,26)$ & $(0,17)$ \\
\hline nción pontami & Feññ & & teralat & & & & & \\
\hline Planes de & & & & & & & & \\
\hline Capital social & 1,10 & 0,92 & 0,93 & $0.618^{* *}$ & 1,05 & 1,80 & 1,04 & 0,98 \\
\hline & $(0,17)$ & $(0,11)$ & $(0,27)$ & $(0,11)$ & $(0,97)$ & $(0,94)$ & $(0,15$ & $(0,12)$ \\
\hline Encontró primer er & España (F & $f=$ otros) & & & & & & \\
\hline & $1.338+$ & 0,93 & 0,96 & 0,77 & 1,40 & 1,05 & 0,90 & 1,15 \\
\hline amigos & $(0,21)$ & $(0,11)$ & $(0,25)$ & $(0,13)$ & $(0,75)$ & $(0,39)$ & $(0,14)$ & $(0,15)$ \\
\hline
\end{tabular}


Tabla 4.

(Continuación)

\begin{tabular}{|c|c|c|c|c|c|c|c|c|}
\hline \multirow[t]{2}{*}{ Variable } & \multicolumn{2}{|c|}{$\begin{array}{c}\text { Cambio en todas las } \\
\text { ocupaciones }\end{array}$} & \multicolumn{2}{|c|}{$\begin{array}{l}\text { Cambio entre } \\
\text { segmentos }\end{array}$} & \multicolumn{2}{|c|}{$\begin{array}{l}\text { Cambio dentro del } \\
\text { segmento primario }\end{array}$} & \multicolumn{2}{|c|}{$\begin{array}{l}\text { Cambio dentro del } \\
\text { segmento secundario }\end{array}$} \\
\hline & Desc. & Asc. & Desc. & Asc. & Desc. & Asc. & Desc. & Asc. \\
\hline (1) & (2) & (3) & (4) & (5) & (6) & (7) & (8) & (9) \\
\hline \multicolumn{9}{|l|}{ Mercado de trabajo } \\
\hline \multirow{2}{*}{$\begin{array}{l}\text { Tiempo en el empleo } \\
\text { actual (en años) }\end{array}$} & 1,03 & 0,97 & 0,99 & 0,95 & 0,96 & $0.874^{*}$ & 1,01 & 1,02 \\
\hline & $(0,03)$ & $(0,02)$ & $(0,07)$ & $(0,03)$ & $(0,07)$ & $(0,05)$ & $(0,04)$ & $(0,03)$ \\
\hline \multirow{2}{*}{$\begin{array}{l}\text { N. }{ }^{\circ} \text { medio contratos año } \\
\text { desde llegada España }\end{array}$} & 0,93 & $0.823+$ & 1,07 & $0.642^{*}$ & 0,68 & $0.134^{*}$ & 0,83 & 0,89 \\
\hline & $(0,15)$ & $(0,09)$ & $(0,33)$ & $(0,12)$ & $(0,32)$ & $(0,13)$ & $(0,13)$ & $(0,11)$ \\
\hline \multicolumn{9}{|c|}{ N. ${ }^{\circ}$ veces desempleo en España (Ref. $=$ Nunca) } \\
\hline \multirow[t]{2}{*}{ Una } & $1.728^{\star \star *}$ & 1,05 & 1,01 & 0,82 & 2,90 & 1,16 & $1.420^{*}$ & 1,19 \\
\hline & $(0,27)$ & $(0,12)$ & $(0,31)$ & $(0,15)$ & $(1,93)$ & $(0,53)$ & $(0,22)$ & $(0,15)$ \\
\hline \multirow[t]{2}{*}{ Más de una } & $2.789^{* \star \star}$ & 1,13 & 0,98 & 1,07 & $6.059+$ & 0,79 & $1.833^{* *}$ & $1.481^{*}$ \\
\hline & $(0,68)$ & $(0,20)$ & $(0,48)$ & $(0,27)$ & $(5,58)$ & $(0,64)$ & $(0,43)$ & $(0,28)$ \\
\hline \multicolumn{9}{|c|}{ Estatus de empleo (Ref.=empleadores y otros) } \\
\hline \multirow[t]{2}{*}{ Empleados } & 0,80 & 0,92 & 1,02 & 0,83 & 0,97 & $7.532+$ & 0,85 & 0,78 \\
\hline & $(0,17)$ & $(0,13)$ & $(0,30)$ & $(0,18)$ & $(0,68)$ & $(7,95)$ & $(0,17)$ & $(0,13)$ \\
\hline \multicolumn{9}{|c|}{ Ocupación en empleo anterior (Ref.=Trabajadores Servicios restauración, personales y vendedores comercio) } \\
\hline \multirow{2}{*}{$\begin{array}{l}\text { Directivos de empresas } \\
\text { y profesionales }\end{array}$} & 1,11 & $0.178^{* \star *}$ & & & & & & \\
\hline & $(0,31)$ & $(0,08)$ & & & & & & \\
\hline \multirow{2}{*}{$\begin{array}{l}\text { Técnicos de Apoyo y } \\
\text { empleados administrativos }\end{array}$} & $2.554^{\star *}$ & 0,81 & & & & & & \\
\hline & $(0,73)$ & $(0,23)$ & & & & & & \\
\hline \multirow{2}{*}{$\begin{array}{l}\text { Trabajadores cualificados } \\
\text { agricultura e industria }\end{array}$} & $0.343^{\star \star \star}$ & 0,92 & & & & & & \\
\hline & $(0,09)$ & $(0,22)$ & & & & & & \\
\hline \multirow{2}{*}{$\begin{array}{l}\text { Trabajadores no } \\
\text { cualificados }\end{array}$} & 0 0** & $5.175^{\star \star *}$ & & & & & & \\
\hline & 0,00 & $(0,97)$ & & & & & & \\
\hline \multicolumn{9}{|c|}{ Sector de actividad del empleo anterior (Ref.=Servicios) } \\
\hline \multirow[t]{2}{*}{ Manufactura } & 1,29 & 1,15 & $0.304^{*}$ & $0.540^{*}$ & 1,87 & 2,03 & 0,72 & 1,23 \\
\hline & $(0,40)$ & $(0,32)$ & $(0,17)$ & $(0,16)$ & $(1,88)$ & $(1,24)$ & $(0,19)$ & $(0,31)$ \\
\hline \multirow{2}{*}{$\begin{array}{l}\text { Agricultura y } \\
\text { Construcción }\end{array}$} & 0,71 & $0.710+$ & $0.0519^{\star \star \star}$ & $0.462^{* *}$ & 2,87 & $6.297+$ & $0.231^{* * *}$ & $1.365+$ \\
\hline & $(0,20)$ & $(0,14)$ & $(0,03)$ & $(0,12)$ & $(3,64)$ & $(6,33)$ & $(0,05)$ & $(0,26)$ \\
\hline \multirow{2}{*}{$\begin{array}{l}\text { Hogares con Servicio } \\
\text { doméstico }\end{array}$} & $1.963^{* *}$ & $0.479^{* * *}$ & $0.0790^{*}$ & $0.664+$ & $0.000^{* * *}$ & $0.000^{* * *}$ & $0.576^{* *}$ & 1,32 \\
\hline & $(0,43)$ & $(0,09)$ & $(0,09)$ & $(0,14)$ & $(0,00)$ & $(0,00)$ & $(0,11)$ & $(0,24)$ \\
\hline Características demográfic & & & & & & & & \\
\hline Género (Ref.=mujeres) & & & & & & & & \\
\hline Hombres & $1.462^{*}$ & 1,20 & 1,49 & $0.642^{*}$ & 0,91 & 1,26 & 1,29 & 1,22 \\
\hline & $(0,26)$ & $(0,18)$ & $(0,46)$ & $(0,13)$ & $(0,48)$ & $(0,58)$ & $(0,24)$ & $(0,21)$ \\
\hline Edad & 0,99 & $0.975^{\star \star *}$ & $0.965^{*}$ & $0.954^{* * \star}$ & 1,02 & 0,98 & $0.983^{*}$ & $0.981^{* *}$ \\
\hline & $(0,01)$ & $(0,01)$ & $(0,02)$ & $(0,01)$ & $(0,04)$ & $(0,02)$ & $(0,01)$ & $(0,01)$ \\
\hline Estatus marital (Ref. $=s \mathrm{C}$ & & & & & & & & \\
\hline Casado & 0,92 & $1.233+$ & 0,79 & 1,14 & 1,41 & 2,11 & 1,11 & 1,01 \\
\hline & $(0,16)$ & $(0,15)$ & $(0,21)$ & $(0,21)$ & $(0,98)$ & $(1,16)$ & $(0,18)$ & $(0,14)$ \\
\hline $\mathrm{N} .^{\circ}$ de menores en el & $1.188^{*}$ & 1,09 & 1,06 & 1,07 & 0,96 & 0,71 & $1.139+$ & $1.141^{*}$ \\
\hline hogar & $(0,08)$ & $(0,06)$ & $(0,17)$ & $(0,09)$ & $(0,26)$ & $(0,15)$ & $(0,08)$ & $(0,07)$ \\
\hline $\mathrm{N}$ & & & 3.6 & 61 & & 32 & & \\
\hline F test & 7951. & $00^{* * *}$ & 26.8 & $5^{\star \star \star}$ & & $5^{* \star *}$ & & \\
\hline
\end{tabular}

Fuente: Elaboración propia a partir de microdatos de la Encuesta Nacional de Inmigrantes 2007.

${ }^{* * *} p<0.001,{ }^{* *} p<0.01,{ }^{*} p<0.05,+p<0.1$ 
tes procedentes de Marruecos y de América Latina tienen mayor propensión a subir de segmento que los europeos no UE. Estos resultados son algo distintos en los modelos de los segmentos, donde los africanos (sin Marruecos) tienen nulas probabilidades de descender en el primario y de bajar en el secundario (probablemente porque ya ocupan las posiciones más bajas).

La duración de la estancia en España se correlaciona negativamente con la movilidad descendente de los inmigrantes en la segunda transición. Por cada año adicional que un inmigrante pasa en España disminuyen sus probabilidades de movilidad descendente y aumentan las de movilidad ascendente. Los efectos de la duración de la estancia en España en la movilidad ocupacional por segmentos no son estadísticamente significativas, pero apuntan en la misma dirección.

La documentación marca una pauta clara: los ciudadanos de la UE tienen mayores probabilidades de movilidad ascendente y menos de descendente: así la estimación de la movilidad ascendente de los residentes permanentes y otros documentados es $R R R=0,677$ y la de los indocumentados es $R R R=0,462$. Estas pautas se repiten por segmentos y es especialmente significativo para la menor probabilidad de ascenso que tienen los indocumentados en la movilidad entre segmentos y en el segmento secundario. Se reproduce así la misma jerarquía de oportunidades desiguales que en la primera transición.

Los que emigran por razones de empleo tienen mayores probabilidades de movilidad ascendente y descendente en el modelo general (aunque los datos no sean significativos) que los que migraron por otras razones; esto se reproduce en el segmento secundario pero no en el primario, donde ocurre lo contrario y los datos muestran una significativa menor propensión de descenso ocupacional. La intención de asentarse en España favorece la movilidad descendente y dificulta la ascendente, tanto en el modelo general como en el segmento secundario, pero no así en el modelo del primario en que ocurre lo contrario. Es significativa la menor probabilidad de ascenso ocupacional entre segmentos que tienen los que tienen intención de asentamiento.

\section{Capital social}

Los que encuentran su primer empleo a través de redes familiares y de amigos siguen siendo más propensos a experimentar movilidad descendente en la segunda transición que los que encontraron su trabajo a través de otros canales (aunque este efecto es solo marginalmente significativo). El efecto es opuesto en el segmento secundario y distinto en el primario (porque también favorece una mayor movilidad ascendente).

\section{Mercado de trabajo}

Para la segunda transición se han incluido varias variables sobre la experiencia laboral de los inmigrantes en España. El tiempo que llevan en el empleo actual no está significativamente relacionado con la movilidad ocupacional de los inmigrantes, aunque 
muestra pautas distintas en los segmentos primario y secundario respecto al modelo general y, sobre todo, muestra cómo disminuyen las probabilidades de ascenso en el segmento primario. El número medio de contratos por año muestra que una mayor rotación en contratos laborales está asociada a una menor probabilidad de movilidad ocupacional, especialmente ascendente entre segmentos y en el segmento primario. El número de veces que los inmigrantes han estado en situación de desempleo en España tiene efectos muy significativos porque hace aumentar las probabilidades de movilidad descendente, especialmente entre quienes han estado más de una vez en paro (RRR $=2,786)$ y, aunque los datos no sean significativos, muestran también una mayor probabilidad de movilidad ascendente en esta segunda transición en el modelo general. Esta pauta se repite en el secundario con datos bastante significativos, pero no en el primario.

Se ha incluido en el modelo general la ocupación (como control) y el sector de actividad del primer empleo en España. En el modelo general las personas empleadas en servicio doméstico son más propensas a experimentar movilidad descendente y menos propensas a experimentar movilidad ascendente que los que trabajaban en el sector servicios, en relación con los que no tuvieron movilidad ocupacional en el modelo general. También son menos propensos a experimentar movilidad entre los segmentos. Pero los resultados se invierten en la movilidad descendente y ascendente en el mercado de trabajo secundario y es especialmente significativo la menor propensión descendente (RRR $=0,576)$. Los trabajadores cuyo primer empleo en España fue en la agricultura 0 en la construcción son menos propensos a experimentar movilidad entre segmentos y movilidad descendente en el secundario (pero tienen pautas distintas en el primario). Los que trabajaban en manufacturas son menos propensos a experimentar movilidad entre segmentos.

\section{Características demográficas}

Los hombres inmigrantes tienen mayor propensión a experimentar movilidad descendente que las mujeres en el modelo general; tienen una menor propensión a ascender entre segmentos. La edad está negativamente relacionada con la movilidad ocupacional en la segunda transición: cada año adicional disminuye la probabilidad de movilidad en el modelo general y es especialmente significativa en la movilidad ascendente $(R R R=0,975)$; esta pauta se repite en el secundario pero no en el primario. El número de niños menores de 16 años en el hogar está asociado con mayor movilidad ocupacional descendente en el modelo general y ascendente en el secundario. La tabla de síntesis (tabla 5) pretende mostrar de modo claro (aunque algo simplificado) los resultados generales de las regresiones. Para ello se comparan para ambas transiciones si las pautas de las RRR ascendente y descendente de los modelos del segmento primario $(\mathrm{P})$ y del segmento secundario (S) se comportan de manera similar, de manera distinta o de manera opuesta a los modelos generales (en relación a la inmovilidad general). La tabla pretende facilitar la visualización de los resultados expuestos en las tablas 3 y 4 
para permitir un mejor contraste de los resultados de los modelos con la hipótesis de investigación ${ }^{4}$.

\section{Tabla 5.}

Síntesis comparativa de los resultados de las regresiones.

\begin{tabular}{|c|c|c|c|c|c|c|}
\hline \multirow[t]{2}{*}{ Variables } & \multicolumn{3}{|c|}{ Primera transición } & \multicolumn{3}{|c|}{ Segunda transición } \\
\hline & Opuesto & Distinto & Similar & Opuesto & Distinto & Similar \\
\hline Educación & & PS & & & PS & \\
\hline Certificado estudios España & $P$ & & S & $P$ & $S$ & \\
\hline Región de orígen & & $P$ & $S$ & PS & & \\
\hline Período de llegada & & $S$ & $P$ & -- & -- & -- \\
\hline Tiempo en España & -- & -- & -- & & & PS \\
\hline Ciudadanía & & $P$ & $S$ & & $P$ & $S$ \\
\hline Razón de migrar & & $P$ & $S$ & $\mathrm{P}$ & & $S$ \\
\hline Intención asentam. en España & $P$ & & S & & $\mathrm{P}$ & S \\
\hline Encuentra trabajo por redes & & & PS & S & $\mathrm{P}$ & \\
\hline Búsqueda de empleo & & $P$ & $S$ & -- & -- & -- \\
\hline Tiempo en empleo actual & -- & -- & -- & & PS & \\
\hline Media número contratos & -- & -- & -- & & & PS \\
\hline N. ${ }^{0}$ veces desempleado & - & -- & -- & & $P$ & S \\
\hline Estatus empleo & & $P$ & $S$ & & $P$ & $S$ \\
\hline Sector empleo previo & & $\mathrm{P}$ & S & PS & & \\
\hline Género & & S & $\mathrm{P}$ & & $P$ & S \\
\hline Edad & & & PS & & $P$ & $S$ \\
\hline Estatus conyugal & $P$ & S & & & PS & \\
\hline N. ${ }^{\circ}$ menores en hogar & & PS & & $P$ & & $S$ \\
\hline
\end{tabular}

Nota:

Similar: Los resultados de los modelos de regresión ascendente y descendente de los segmentos primario (P) y secundario (S) tienen el mismo sentido que los del modelo general (es decir, si es superior o inferior a 1). Opuesto: Cuando los resultados del P o del S apuntan en la dirección contraria (si son superiores al valor de referencia en el modelo general, son inferiores en el modelo de alguno de los segmentos y viceversa) Distinto: Cuando alguno de los resultados de las regresiones del $\mathrm{P}$ o del $\mathrm{S}$ son diferentes (pero no todos opuestos) al modelo general.

${ }^{4}$ Debido a las dificultades en la comparación de coeficientes entre modelos, se estimaron las probabilidades para cada resultado: movilidad descendente, ascendente e inmovilidad; para cada categoría de las variables contenidas en el análisis se hicieron pruebas de hipótesis sobre las diferencias entre el modelo general y los modelos entre y por segmentos. 


\section{CONCLUSIONES}

En este artículo hemos examinado los determinantes de la pauta de movilidad ocupacional "segmentada" en forma de "U" de los inmigrantes no comunitarios en España en las dos transiciones (entre el último empleo en origen y el primer empleo en España y entre este y el empleo en el momento de la encuesta) intentado responder a la pregunta de si esos determinantes juegan un papel diferente en los distintos segmentos y en las dos transiciones. Para ello, a partir de la Encuesta Nacional de Inmigrantes 2007 que recoge datos retrospectivos de los inmigrantes en España, se han estimado modelos logísticos multinomiales para la movilidad descendente y ascendente (versus inmovilidad), primero para el conjunto de la muestra (modelos generales) y luego para la movilidad entre segmentos y para la movilidad dentro del segmento primario y del secundario, tanto para la primera como para la segunda transición.

Los resultados de los modelos generales son muy congruentes con la literatura más consolidada en este campo. Las variables de capital humano muestran el papel de filtro, de resguardo y de impulso que cumple el nivel educativo: filtro para acceder a las ocupaciones no manuales, resguardo porque protege contra la movilidad descendente, e impulso porque favorece las probabilidades de ascenso ocupacional; además, tener certificado de estudios abre puertas de ascenso ocupacional y, en el segundo momento, esas puertas se expanden si se homologan los certificados y sobre todo si se han obtenido en España. Distintas variables de la experiencia migratoria se muestran muy relevantes en las dos transiciones. Por ejemplo, la jerarquía de oportunidades desiguales según la zona de origen con menores probabilidades de descenso y mayores de ascenso según se provenga del resto del mundo, de América Latina, de la Europa no comunitaria, de Marruecos o de otros países africanos. El período de llegada muestra un efecto "saturación" y hace que aumenten ligeramente las probabilidades de descenso para los que llegan en los años 2000. El tiempo que llevan los inmigrantes en España hace que cada año aumente ligeramente la probabilidad de movilidad ocupacional ascendente y que disminuya la descendente. Ser ciudadano de la UE o tener residencia legal en España mejora las expectativas ocupacionales; por el contrario, ser indocumentado tiene un efecto "castigo" ocupacional que se refleja en mayores probabilidades de descenso en la primera transición y en menores de contramovilidad ascendente posterior. Haber migrado por razones de empleo hace que los inmigrantes logren mantenerse más en los grupos ocupacionales de origen. El capital social muestra su papel ambivalente: ayuda a buscar empleo pero hace que los que lo encuentran a través de redes familiares o de amigos tengan más movilidad descendente en las dos transiciones. Algunas variables del mercado de trabajo muestran un alto poder predictivo: los que llegan con contrato en origen o tienen capacidad (social) para estar mucho tiempo buscando empleo sufren menos movilidad descendente; de la misma manera, los que han estado en paro ven aumentar sus probabilidades de descenso ocupacional. Dos variables demográficas son especialmente relevantes: el 
género y la edad. El género muestra cómo las mujeres tienen una mayor propensión a sufrir movilidad descendente inicial, y la edad se muestra relevante en la segunda transición y apunta a cómo disminuye la probabilidad de descenso y sobre todo de ascenso ocupacional por cada año que se cumple.

Pero el argumento central de nuestra hipótesis era que estos determinantes de la movilidad ocupacional descendente y ascendente podrían comportarse de modo diferente cuando se analizan de modo separado para la movilidad dentro de los segmentos primario y secundario y en la movilidad entre segmentos. Esperábamos que algunas variables independientes - como el capital humano, experiencia migratoria, capital social, mercado de trabajo o algunas características demográficas- se comportaran de modo similar, pero que otras pudieran hacerlo de modo distinto e incluso de manera opuesta en los diferentes modelos. Y eso es a lo que apuntan las regresiones: muchas variables se comportan de modo similar en el modelo general y en otros modelos, de modo especial las regresiones del secundario: es el caso en ambas transiciones de la ciudadanía, la razón para migrar, la intención de asentamiento en España, el estatus del empleo o la edad. Pero hay otras variables que se comportan de modo distinto en el modelo general y en los segmentos, especialmente en el primario: es el caso en las dos transiciones de la educación, la ciudadanía o el estatus de empleo. Unas pocas variables se comportan incluso de modo opuesto, sobre todo en el primario.

Estos resultados muestran otra cuestión relevante: el efecto "disimulador" que se produce si únicamente se analizan los datos agregados en los modelos generales. Porque los datos de esos modelos pueden estar agregando efectos que actúan en direcciones distintas u opuestas, y una desagregación en segmentos como la que se ha propuesto en este texto contribuye a desvelarlo.

Estas conclusiones son relevantes para las políticas de gestión de la inmigración y muestran la importancia de desarrollar instrumentos eficaces de gestión de los flujos migratorios y políticas laborales de carácter general pero que tengan en cuenta las características específicas de la inmigración. Y también políticas de integración más generales que favorezcan la igualdad de todas las personas con respecto a la diversidad cultural que la inmigración ha aportado a nuestras sociedades (Cachón 2009; AysaLastra y Cachón 2011).

Nuestro análisis de los determinantes apunta a la existencia de distintas pautas de movilidad, lo que hemos llamado movilidad ocupacional "segmentada" en forma de "U", entre la movilidad descendente de la primera transición y la contramovilidad ascendente limitada de la segunda transición y una relevancia distinta de los factores en diferentes segmentos del mercado de trabajo. Pero se debería continuar trabajando con muestras más amplias (especialmente para el segmento primario) y con datos de otros países para contrastar los resultados obtenidos en este trabajo. También sería relevante analizar comparativamente datos antes y después de la gran recesión que comenzó en 2007. 


\section{Referencias Bibliográficas}

Adsera, A. y B. R. Chiswick. 2007. "Are there gender and country of origin differences in immigrant market outcomes across European destinations?." Journal of Population Economics 20:495526.

Aguilera, M. B. y D. Massey. 2003. "Social capital and the Wages of Mexican Migrants: New Hypotheses and Tests." Social Forces 82:671-701.

Allensworth, E. M. 1997. "Earnings Mobility of First and '1.5' Generation Mexican-Origin Women and Men: A Comparison with U.S.-Born Mexican Americans and Non-Hispanic Whites." International Migration Review 31:386-410.

Aslund, O. y D-O Rooth. 2007. "Do when and where matter? Initial Labour Market Conditions and Immigrant Earnings." The Economic Journal 117:422-448.

Aysa-Lastra, M. y L. Cachón. 2011. "El impacto de la crisis global en el mercado de trabajo de los inmigrantes latinoamericanos en Estados Unidos y en España." Revista del Ministerio de Trabajo e Inmigración 95:47-82.

Aysa-Lastra, M. y L. Cachón. 2012. "Latino Immigrant Employment During the Great Recession: A Comparison between the United States and Spain." Norteamérica 14:7-42.

Aysa-Lastra, M. y L. Cachón (en prensa). "Movilidad ocupacional segmentada: el caso de los inmigrantes no comunitarios en España." Revista Española de Investigaciones Sociológicas.

Barrett, A. y D. Duffy. 2008. "Are Ireland's Immigrants Integrating into Its Labour Market?." International Migration Review 42:597-619.

Beenstock, M., B. R. Chiswick y A. Paltiel. 2010. "Testing the immigrant assimilation hypothesis with longitudinal data." Review of Economics of the Household 8:7-27.

Borjas, G. 1995. "Assimilation and Changes in Cohort Quality Revisited: What Happened to Immigrant Earnings in the 1980s?." Journal of Labor Economics 13:201-245.

Borjas G. J. 1999. "The Economic Analysis of Immigration". Pp. 1697-1760 en Handbook of Labor Economics, vol. 3A, editado por O. Ashenfelter y D. Card. Amsterdam: Elsevier.

Boston, T. 1990. "Segmented Labor Markets: New Evidence from a Study of Four Race-Gender Groups." Industrial and Labor Relations Review 44:99-115.

Cachón, L. 2009. La "España inmigrante": marco discriminatorio, mercado de trabajo y políticas de integración. Barcelona: Anthropos.

Cachón, L. 2012. "La inmigración de mañana en la España de la Gran Recesión y después." Panorama Social 16:71-83.

Caparrós, A. y M. L. Navarro. 2010. "Movilidad ocupacional de los inmigrantes en España." Investigaciones de Economía de la Educación 5:873-890.

Chiswick, B. R. 1977. "A Longitudinal Analysis of the Occupational Mobility of Immigrants." Pp. 20-27 en Proceedings of the 30th Annual Winter Meetings, Industrial Relations Research Association, editado por B. D. Dennis. Madison WI: IRRA. 
Chiswick, B. R. 1978. "The Effect of Americanization on the Earnings of Foreign-born Men." The Journal of Political Economy 86:897-921.

Chiswick, B. R. 1979. "The Economic Progress of Immigrants: Some Apparently Universal patterns". Pp. 357-399 en Contemporary Economic Problems 1979, dirigido por W. Fellner. Washington DC: American Enterprise Institute for Public Policy Research.

Chiswick, B. R. 1997. "The Economics of Immigrant Skill and Adjustment." The Quarterly Review of Economics and Finance 37:183-188.

Chiswick, B. R. 1999. "Immigration Policy and Immigrant Quality. Are Immigrants Favorably SelfSelected?." American Economic Review 89:181-185.

Chiswick, B. R., Y. Lee and P. Miller. 2005. "A Longitudinal Analysis of Immigrant Occupational Mobility: A Test of the Immigrant Assimilation Hypothesis." International Migration Review 39:332-353.

Cobb-Clark, D. A y S. A. Kossoudji. 2000. "Mobility in El Norte: The Employment and Occupational Changes of Unauthorized Latin American Women." Social Science Quarterly 811:311-324.

Colectivo IOE 2010. "Las migraciones laborales hacia España." Pp. 359-498 en Encuesta Nacional de Inmigrantes 2007: el mercado laboral y las redes sociales. Madrid: MTIN.

Constant, A. y D. Massey. 2003. "Self-selection, earnings, and out-migration: A longitudinal study of immigrants to Germany." Journal of Population Economics 16:631-653.

Djamba, Y. K., S. Goldstein y A. Goldstein. 2000. "Migration and Occupational Change During Periods of. Economic Transition: Women and Men in Vietnam". Asian and Pacific Migration Journal 9:65-92.

Duleep, H. y M. Regets. 1997. "The Decline in Immigrant Entry Earnings: Less Transferable Skills or Lower Ability?." The Quarterly Review of Economics and Finance 37:189-208.

Erikson, R. y J. H. Goldthorpe. 1992. The Constant Flux: A Study of Class Mobility in Industrial Societies. Oxford: Clarendon.

Fassmann, H. 1997. "Is the Austrian Labour Market Ethnically Segmented?." European Journal of Population 13:17-32.

Friedberg, R. M. 2000. "You Can't Take It with You? Immigrant Assimilation and the Portability of Human Capital." Journal of Labor Economics 18:221-251.

Girod, R. 1971. Mobilité sociales. Faits establis et problems sociales. Ginebra: Droz.

Goldthorpe, J. H. 2010. De la sociología. Números, narrativas e integración de la investigación y la teoría. Madrid: CIS.

Hatton, T. J y A. Leigh. 2011. "Immigrants assimilate as communities, not just as individuals." Journal of Population Economics 24:389-419.

Long J. E. 1980. "The Effect of Americanization on Earnings: Some Evidence for Women." Journal of Political Economy 883:620-629.

Mahuteau, S. y P. Junankar. 2008. "Do Migrants succeed in the Australian Labour Market? Further Evidence on Job Quality." Paper 8703, MPRA, Universidad de München: München.

Massey, D. S. y M. Aysa-Lastra. 2011. "Social Capital and International Migration from Latin America." International Journal of Population Research, Volume 2011, Article ID 834145. 
McAllister, I. 1995. "Occupational Mobility among Immigrants: The impact of Migration on Economic Success in Australia." International Migration Review 29:441-468.

Miller, S. I. 1980. "The calculation of mobility rates as applied to Boudon's models." Sociologia Internationalis 18:35-47.

Modood, T. 1998. "Ethnic diversity and racial disadvantages in employment." Pp. 53-73 en Race relations in Britain. A development agenda, editado por T. Blackstone, B. Parekh y P. Sanders. Londres: Routledge.

Mullan, B. 1989. "The Impact of Social Networks on the Occupational Status of Migrants." International Migration 27:69-86.

Nee, V. y J. M. Sanders. 2001. "Understanding the diversity of immigrant incorporation: a forms-ofcapital model." Ethnic and Racial Studies 24:386-411.

Parkin, F. 1978. Orden político y desigualdades de clase. Madrid: Debate.

Portes, A. 2000. "The Two Meanings of Social Capital." Sociological Forum 1:1-12.

Powers, M. G. y W. Seltzer. 1998. "Occupational Status and Mobility among Undocumented Immigrants by Gender." International Migration Review 321:21-55.

Raijman, R. y M. Semyonov. 1997. "Gender, Ethnicity, and Immigration: Double Disadvantage and Triple Disadvantage among Recent Immigrant Women in the Israeli Labor Market". Gender and Society 111:108-125.

Redstone, I. 2006. "Occupational Mobility among Legal Immigrants to the United States." International Migration Review 40:854-884.

Redstone, I. 2008. "Occupational Trajectories of Legal US Immigrants: Downgrading and Recovery." Population and Development Review 34:435-456.

Reyneri, E. y G. Fullin. 2011. "Labour Market Penalties of New Immigrants in New and Old Receiving West European Countries." International Migration 49:32-57.

Rosenberg, S. 1980. "Male Occupational Standing and the Dual Labor Market." Industrial Relations 19:34-49.

Sanromá, E., R. Ramos y H. Simón. 2009. "Los salarios de los inmigrantes en el mercado de trabajo español ¿Importa el origen del capital humano?." Document de Treball, Xarxa de Refèrencia en Economía Aplicada 4, Departament d'Innovació, Universitats i Empresa, Generalitat de Catalunya.

Simón, H., R. Ramos y E. Sanromá. 2010. "Movilidad ocupacional de los inmigrantes en una economía de bajas cualificaciones. El caso de España." Document de Treball, Xarxa de Refèrencia en Economía Aplicada 6, Departament d'Innovació, Universitats i Empresa, Generalitat de Catalunya.

Stanek, M. y A. Veira. 2009. "Occupational Transitions and Social Mobility at Migration to Spain." Documento de Trabajo GEPS N. ${ }^{\circ} 4 / 2009$ III, Universidad Complutense de Madrid.

Suto, M. 2009. "Compromised careers: The occupational transition of immigration and resettlement." Work 32:417-429.

Tienda, M. y A. Singer. 1995. "Wage Mobility of Undocumented Workers in the United States." International Migration Review 29:112-138. 
Weber, M. [1922] 1969. Economía y sociedad. Esbozo de sociología comprensiva. México: FCE.

Weiss, Y., R. M. Sauer y M. Gotlibovski. 2003. "Immigration, Search, and Loss of Skill." Journal of Labor Economics 21:557-592.

Maria Aysa-Lastra es profesora asistente de sociología en el departamento de Estudios Globales y Socioculturales de Florida International University (Estados Unidos). Ha estudiado la inmigración latina en los Estados Unidos y actualmente desarrolla estudios comparados de las poblaciones de origen latinoamericano residentes en América del Norte y Europa. Sus trabajos se han publicado recientemente en Norteamérica, International Journal of Population Research, Journal of Family Violence, Rural Sociology y Journal of Refugee Studies, entre otros.

Lorenzo Cachón Rodríguez es catedrático de sociología de la Universidad Complutense de Madrid. Sus dos últimos libros son: Inmigración y conflictos en Europa: Aprender para una mejor convivencia (Hacer, 2011) y La España inmigrante: marco discriminatorio, mercado de trabajo y políticas de integración (Anthropos, 2009). Sus líneas actuales de investigación son inmigración y mercado de trabajo; políticas de inmigración y de integración de los inmigrantes; discriminación y políticas antidiscriminatorias; y conflictos ligados a la inmigración.

RECIBIDO: 03/05/2012

ACEPTADO: 07/11/2012

Publicado on-line: 16/04/2013 